\title{
Inelastic compaction and permeability evolution in volcanic rock
}

\author{
Jamie I. Farquharson, Patrick Baud, and Michael J. Heap \\ Institut de Physique de Globe de Strasbourg (UMR7516 CNRS), EOST, Université de Strasbourg, France
}

Correspondence to: Jamie I. Farquharson (farquharson@ unistra.fr)

Received: 1 December 2016 - Discussion started: 19 December 2016

Revised: 29 March 2017 - Accepted: 7 April 2017 - Published: 27 April 2017

\begin{abstract}
Active volcanoes are mechanically dynamic environments, and edifice-forming material may often be subjected to significant amounts of stress and strain. It is understood that porous volcanic rock can compact inelastically under a wide range of in situ conditions. In this contribution, we explore the evolution of porosity and permeability - critical properties influencing the style and magnitude of volcanic activity - as a function of inelastic compaction of porous andesite under triaxial conditions. Progressive axial strain accumulation is associated with progressive porosity loss. The efficiency of compaction was found to be related to the effective confining pressure under which deformation occurred: at higher effective pressure, more porosity was lost for any given amount of axial strain. Permeability evolution is more complex, with small amounts of stress-induced compaction $(<0.05$, i.e. less than $5 \%$ reduction in sample length) yielding an increase in permeability under all effective pressures tested, occasionally by almost 1 order of magnitude. This phenomenon is considered here to be the result of improved connectivity of formerly isolated porosity during triaxial loading. This effect is then overshadowed by a decrease in permeability with further inelastic strain accumulation, especially notable at high axial strains $(>0.20)$ where samples may undergo a reduction in permeability by 2 orders of magnitude relative to their initial values. A physical limit to compaction is discussed, which we suggest is echoed in a limit to the potential for permeability reduction in compacting volcanic rock. Compiled literature data illustrate that at high axial strain (both in the brittle and ductile regimes), porosity $\phi$ and permeability $k$ tend to converge towards intermediate values (i.e. $0.10 \leq \phi \leq 0.20 ; 10^{-14} \leq k \leq 10^{-13} \mathrm{~m}^{2}$ ). These results are discussed in light of their potential ramifications for impacting edifice outgassing - and in turn, eruptive activity - in active volcanoes.
\end{abstract}

\section{Introduction}

Active volcanoes are inherently high-strain environments (e.g. Omori et al., 1920; Mogi, 1958; Dzurisin, 2003). Magma is a constantly developing multi-phase medium, and as it migrates through the crust, vesiculating and crystallising along the way, it can impart significant mechanical stress on the surrounding edifice rock (e.g. Sparks, 1997; Voight et al., 1998; Denlinger and Hoblitt, 1999; Clarke et al., 2007; Heimisson et al., 2015). Deeper in the crust, magma chamber deformation can pressurise conduit and dyke systems above, in turn displacing the edifice (e.g. Melnik and Sparks, 1999, 2005; Wadge et al., 2006). Much of the edifice is likely to be fluid-saturated (e.g. Day, 1996; Delcamp et al., 2016), a function of permeability, permeability anisotropy, and heat flux (Hurwitz et al., 2003; Finn et al., 2007): migration of fluids can serve to adjust the in situ stress conditions and influence the short-term failure strength of edifice-forming rocks (e.g. Farquharson et al., 2016a). Moreover, the continued loading of the edifice due to iterative emplacement of erupted material will serve to increase the overburden (i.e. the confining pressure) in any given region of the edifice (e.g. Heap et al., 2015a). It is generally understood that all volcanoes deform under their own weight to some extent (Shteynberg and Solov'yev, 1976; Dieterich, 1988; van Wyk de Vries and Borgia, 1996), driven largely by gravitational spreading and substratum flexure (van Wyk de Vries and Matela, 1998), which indicates that the local and far-field stresses operating in a volcanic edifice will evolve over time. Furthermore, the overlying stress may be influenced by loading and unloading of volcanoes by ice, for example, either seasonally or due to longer-scale climatic variations (e.g. Sigmundsson et al., 2010).

Thus, edifice-forming volcanic rock may be subjected to a range of stress conditions over time. This is an important 
consideration, as the response of rock to imposed stress can have a significant impact on its fluid transport properties. In particular, permeability - the capacity of a material to transmit fluids through interconnected pore space - is a critical property in the context of volatile loss and pressure dissipation. The expansion of exsolved gas species, which occurs as volatile-laden magma approaches the surface of the Earth, can generate overpressures in the magma: the kinetic engine that typically drives explosive fragmentation (e.g. Sparks, 1978). If the permeability of a volcanic system (including the edifice) is high, volatiles may escape from the magma and the propensity for explosive behaviour may be reduced; conversely, low system permeability could promote pressure build-up and violent eruptive activity, a concept underlying numerous studies in volcanology (for example Eichelberger et al., 1986; Woods and Koyaguchi, 1994; Rust et al., 2004; Edmonds and Herd, 2007; Mueller et al., 2008, 2011; Nguyen et al., 2014; Okumura and Sasaki, 2014; Gaunt et al., 2014).

Volcanic rock can either dilate or compact in response to an applied differential stress or a change in pore pressure. Dilatant brittle failure comprises an increase in porosity through the formation, growth, and coalescence of stressinduced fractures (e.g. Fortin et al., 2011). In compression, this culminates in an axial split or shear fracture. Conversely, an overall reduction in porosity can be brought about by homogeneous or localised inelastic compaction. In Yakuno basalt, Shimada et al. (1989) showed that ductile deformation was associated with distributed microcracking, granulation, and pore occlusion. The underlying physical mechanism - cataclastic pore collapse - is described in detail by Zhu et al. (2010) and has since been interpreted in triaxially deformed tuff (Zhu et al., 2011; Alam et al., 2014; Heap et al., 2015b), basalt (Adelinet et al., 2013; Zhu et al., 2016), andesite (Heap et al., 2015a, 2017), trachyandesite (Loaiza et al., 2012), and dacite (Heap et al., 2016). This micromechanism can be distributed (e.g. Zhu et al., 2011; Heap et al., 2015b) or localised (e.g. Loaiza et al., 2012; Adelinet et al., 2013; Heap et al., 2015a) in the form of bands of compacted pores. The predisposition for strain localisation in volcanic rock has been suggested as a function of stress nucleation around equant porosity (Adelinet et al., 2013), due to preferential alignment of pores (Loaiza et al., 2012), or along pre-existing planes of weakness, such as zones of amoeboid pores (pores that are rounded but highly irregular in shape) or microfractures (Heap et al., 2015a).

While manifestations of inelastic compaction tend not to be immediately obvious in the field (unlike fractures, which are ubiquitous at all scales in volcanic environments), abundant indirect evidence for this process exists. Bulk rock density and porosity have been estimated during scientific drilling projects - in concert with gravimetric and other geophysical data - at, for example, Campi Flegrei, Italy (Barberi et al., 1991), and Mount Unzen (Sakuma et al., 2008). These studies highlight a predictable decrease in porosity with in- creasing depth, supported in either case by a general increase in ultrasonic wave velocities with increasing depth, indicative of a reduction in porosity with increasing lithostatic pressure. To date, physical property data at depth in volcanic materials have been obtained predominantly by researchers assessing the suitability of volcanic deposits for hydrocarbon or geothermal energy exploitation. For example, Chen et al. $(2016,2017 a)$ investigated volcanic sequences in the Junggar Basin in western China in order to determine their suitability as gas and petroleum reservoirs. At both sites, the authors note a general decrease in porosity with depth; for example, Chen et al. (2016) report a decrease in porosity from $\sim 0.30$ to $<0.10$ between the surface and $1000 \mathrm{~m}$ depth. Often, the interpretation of logging data from volcanic materials (e.g. Millett et al., 2016) is non-trivial due to the variable quality of density logs and variations in the relationship between density and porosity with depth, alteration, or the intersection of distinct facies (Li et al., 2009), as well as gaps in the stratigraphic record due to incomplete core recovery. An example of a study with an excellent degree of core recovery $-99.7 \%$ - is reported by Jónsson and Stefánsson (1982): these authors calibrate porosity and density data obtained by the Iceland Research Drilling Project from a borehole cored continuously to a depth of 1919 m near Reyðarfjörður in Iceland. To combat small-scale variability arising from the intersection of discrete geological units, Jónsson and Stefánsson (1982) calculate a running average of porosity and density against depth. Notably, the average porosity decreases from 0.13 at $400 \mathrm{~m}$ depth to 0.06 at $1200 \mathrm{~m}$ depth, corresponding to an increase in bulk rock density of approximately $200 \mathrm{~kg} \mathrm{~m}^{-3}$.

The observation that porosity tends to decrease with increasing depth is borne out by experimental deformation studies, which show that the propensity for compactant rather than dilatant - behaviour of volcanic rock is intrinsically linked to the confining pressure under which the sample is deformed (e.g. Shimada et al., 1989; Heap et al., 2015a; Zhu et al., 2016), as well as being heavily reliant on its initial porosity (Heap et al., 2015a; Zhu et al., 2016) and other factors such as temperature (Violay et al., 2012, 2015; Heap et al., 2017) and alteration (Siratovich et al., 2016). In detail, high effective pressures and/or high initial porosity promote ductile behaviour, whereas dilatant brittle failure is favoured in low-porosity volcanic rock deformed under a range of effective pressures. For an in-depth study regarding the influence of effective pressure and porosity on the failure mode of andesite, the reader is referred to Heap et al. (2015a).

While pre-failure permeability has been explored in plutonic (Zoback and Byerlee, 1975; Kiyama et al., 1996; Mitchell and Faulkner, 2008) and volcanic (Faoro et al., 2013) rocks, studies of post-failure permeability change have been generally limited to investigations into sedimentary and synthetic materials (e.g. Mordecai and Morris, 1970; Peach and Spiers, 1996; Zhu and Wong, 1997; Regnet et al., 2015). However, a recent study explored brittle failure in compression of low-to-intermediate-porosity volcanic rock and the 
influence of progressive stress-induced dilation (Farquharson et al., 2016b). Permeability was found to increase with ongoing strain accumulation under triaxial conditions. With regards to the influence of inelastic compaction, research has yielded both decreases (Zhu and Wong, 1997; Baud et al., 2012; Chen et al., 2017b) and increases (Xiaochun et al., 2003 ) in the permeability of porous sandstone. Alam et al. (2014) investigated the permeability evolution of welded tuff from Shikotsu (Hokkaidō prefecture, Japan), finding that permeability decreased monotonically with triaxial compression (both in the dilation and compaction regimes) and that the rate of permeability decrease was tied to the effective pressure under which deformation was performed. Pilot experiments on porous andesite - described in Heap et al. (2015a) - also indicate permeability loss as a result of inelastic compaction. Building on the work of these studies, this contribution investigates the response of the physical properties of volcanic rock - i.e. porosity and permeability - as a function of inelastic compaction under conditions anticipated in volcanic environments. Using a simplified geometry, we use a layered flow model to discuss permeability reduction as a function of compaction localisation. We then expound these results in light of the potential influence of edifice rock compaction on volcanic activity.

\section{Materials and methods}

\subsection{Sample preparation and deformation}

To assess the influence of inelastic compaction on volcanic rock permeability, a porous andesite from Volcán de Colima (Mexico) was used. The construction history, geomorphology, and eruptive style of Volcán de Colima make it a useful analogue for other active andesitic stratovolcanoes around the world, such as Gunung Merapi (Indonesia), Ruapehu (New Zealand), Volcán Rincón de la Vieja (Costa Rica), Santa María (Guatemala), Tungurahua (Ecuador), and many, many more. Core samples were prepared from a block of andesite approximately $1 \mathrm{~m}^{3}$, collected in May 2014 from the La Lumbre debris-flow track (barranca) on the southwestern flank of the volcano. The andesite - referred to as LLB is a vesicular porphyritic andesite containing subhedral phenocrysts and microphenocrysts of unknown age. Bulk geochemical analysis is given in Table 1.

This andesite was chosen because its relatively high initial connected porosity $\phi$ means that it can be deformed in the ductile regime under pressure conditions relevant to a volcanic edifice (Heap et al., 2015a). With a diameter of $20 \mathrm{~mm}$, 10 sample cores were prepared and were ground flat and parallel to a nominal length of $40 \mathrm{~mm}$. Samples were dried in a vacuum oven for at least $48 \mathrm{~h}$, and the following steps were carried out (adopting the protocol of Farquharson et al., 2016b):
1. Physical properties (porosity, permeability) were measured.

2. Samples were saturated and then deformed triaxially in compression under a set effective pressure to a given degree of axial strain.

3. Samples were unloaded, dried for $48 \mathrm{~h}$, and their permeability was remeasured.

Each of these stages is described in more detail hereafter. Helium pycnometry was used to measure the bulk and powder densities of LLB samples ( $\rho_{\mathrm{b}}$ and $\rho_{\mathrm{p}}$, respectively), whilst measurements of sample dimensions allow the calculation of the bulk volume $V$, and in turn the volumetric mass density $\rho_{\mathrm{v}}$. In turn, porosity (connected $\phi$, total $\phi_{\mathrm{t}}$, and unconnected $\phi_{\mathrm{u}}$ ) can be calculated:

$$
\begin{aligned}
\phi & =\left(\frac{\rho_{\mathrm{b}}-\rho_{\mathrm{v}}}{\rho_{\mathrm{v}}}\right) \\
\phi_{\mathrm{t}} & =1-\left(\frac{\rho_{\mathrm{b}}}{\rho_{\mathrm{p}}}\right) \\
\phi_{\mathrm{u}} & =\phi_{\mathrm{t}}-\phi,
\end{aligned}
$$

where a value of $2653 \pm 0.17 \mathrm{~kg} \mathrm{~m}^{-3}$ is used for $\rho_{\mathrm{p}}$. In detail, helium pycnometry is used to determine the solid volume $V_{\mathrm{s}}$ of each sample, which subsequently allows the calculation of the connected gas porosity $\phi$ as described. Automated measurements of $V_{\mathrm{s}}$ were performed iteratively until five consecutive measurements yielded results within a range of $0.01 \%$ of the sample volume; thus, precision of the pycnometer measurements is high $\left(<0.005 \mathrm{~cm}^{3}\right)$. A greater degree of error arises when manually measuring the sample dimensions, which are required in order to determine $\rho_{\mathrm{v}}$. Repeat measurements allowed an estimation of error in the length and diameter, which typically amount to $<0.05 \mathrm{~cm}^{3}$ in terms of volume. Adopting the notation that $\epsilon_{\phi}$ is the error on the porosity calculation and that $\epsilon_{x}$ and $\epsilon_{y}$ are the independently calculated errors for measurements of $V_{\mathrm{s}}$ and $V$, then the propagated error can be approximated by

$\epsilon_{\phi}=\phi \times\left[\left(\frac{\epsilon_{z}}{V-V_{\mathrm{s}}}\right)^{2}+\left(\frac{\epsilon_{y}}{V}\right)^{2}\right]^{\frac{1}{2}} ; \epsilon_{z}=\left(\epsilon_{x}^{2}+\epsilon_{y}^{2}\right)^{\frac{1}{2}}$.

Values for $\epsilon_{\phi}$ are generally $<0.005$ for the samples described herein. As such, probable error on connected gas porosity measurements is low and always contained within the symbol size when plotted graphically.

Gas permeability was measured under steady-state conditions, with a confining pressure of $1 \mathrm{MPa}$ using the set-up described in Farquharson et al. (2016c). Where necessary, a correction was applied to the measured permeability values to account for turbulent flow (see Forchheimer, 1901), the effects of which can become non-negligible when measuring the permeability of high-porosity media. Section A contains 
Table 1. Major element (oxide) composition, determined via X-ray fluorescence analysis. All values are given in weight percent (wt. \%).

\begin{tabular}{lrrrrrr}
\hline $\mathrm{SiO}_{2}$ & $\mathrm{Al}_{2} \mathrm{O}_{3}$ & $\mathrm{Fe}_{2} \mathrm{O}_{3}$ & $\mathrm{MnO}$ & $\mathrm{MgO}$ & $\mathrm{CaO}$ & $\mathrm{Na}_{2} \mathrm{O}$ \\
\hline 61.260 & 17.330 & 5.745 & 0.100 & 3.725 & 5.505 & 4.455 \\
\pm 0.270 & \pm 0.070 & \pm 0.085 & \pm 0.001 & \pm 0.295 & \pm 0.025 & \pm 0.015 \\
\hline $\mathrm{K}_{2} \mathrm{O}$ & $\mathrm{TiO}_{2}$ & $\mathrm{P}_{2} \mathrm{O} 5$ & $\mathrm{Cr}_{2} \mathrm{O}_{3}$ & $\mathrm{~V}_{2} \mathrm{O}_{5}$ & $\mathrm{NiO}$ & LOI \\
\hline 1.505 & 0.565 & 0.200 & 0.020 & 0.015 & 0.004 & 0.185 \\
\pm 0.035 & \pm 0.015 & \pm 0.020 & \pm 0.005 & \pm 0.005 & \pm 0.001 & \pm 0.215 \\
\hline
\end{tabular}

$\mathrm{SiO}_{2}=$ silicon dioxide. $\mathrm{Al}_{2} \mathrm{O}_{3}=$ aluminium oxide. $\mathrm{Fe}_{2} \mathrm{O}_{3}=$ iron oxide. $\mathrm{MnO}=$ manganese(II)

oxide. $\mathrm{MgO}=$ magnesium oxide. $\mathrm{CaO}=$ calcium oxide. $\mathrm{Na}_{2} \mathrm{O}=$ sodium oxide. $\mathrm{K}_{2} \mathrm{O}=$ potassium

oxide. $\mathrm{TiO}_{2}=$ titanium oxide. $\mathrm{P}_{2} \mathrm{O}_{5}=$ phosphorus pentoxide. $\mathrm{Cr}_{2} \mathrm{O}_{3}=$ chromium(III) oxide.

$\mathrm{V}_{2} \mathrm{O}_{5}=$ vanadium $(\mathrm{V})$ oxide. $\mathrm{NiO}=$ nickel(II) oxide. $\mathrm{LOI}=$ loss on ignition.

further details on the determination of permeability, the application of corrections for inertial effects, and the sources and sizes of potential error in the measurements.

Samples were then encased in a copper foil jacket (which serves to retain bulk sample cohesion after deformation), saturated with distilled water, and loaded into the triaxial deformation rig at Université de Strasbourg (see Fig. 1). Throughout deformation we assume a simple effective stress law, whereby the effective confining pressure $p_{\text {eff }}$ experienced by a sample is a function of the confining pressure $p_{\mathrm{c}}$ around the sample and the pressure of pore fluid $p_{\mathrm{p}}$ within the sample, such that $p_{\text {eff }}=p_{\mathrm{c}}-\alpha \cdot p_{\mathrm{p}}$. Recent experimental work (Farquharson et al., 2016a) shows that $\alpha=1$ is a reasonable assumption for porous andesite.

For each test, the confining and pore pressures were increased slowly until a targeted effective pressure (i.e. hydrostatic pressurisation). Note that pressure is only controlled within the connected porous network (i.e. $\phi$ ). However, we assume that any influence of incomplete sample saturation is negligible due to the relatively small volume of isolated porosity $\phi_{\mathrm{u}}$ in these andesites (see Table 2). Assuming a pycnometry-derived value for bulk density $\rho_{\mathrm{b}}$ of approximately $2100 \mathrm{~kg} \mathrm{~m}^{-3}$, the imposed effective pressures of 10 , 30,50 , and $70 \mathrm{MPa}$ are analogous to depths ranging from the upper $500 \mathrm{~m}$ of the edifice to greater than $3 \mathrm{~km}$ in depth (given that $p_{\mathrm{c}} \propto \rho_{\mathrm{b}} \cdot g \hat{z}$, where $g$ and $\hat{z}$ are surface gravitational acceleration and depth, respectively). The sample was then left overnight to allow microstructural equilibrium. During the deformation experiments, a differential stress was introduced in the direction of the sample axis by advancing an axial piston (see Fig. 1) under servo control, such that the sample is subjected to a constant strain rate of $10^{-5} \mathrm{~s}^{-1}$ (note that hereafter strain refers to axial strain unless otherwise specified). We note that - on the edifice scale - absolute strain rates resulting from magma migration and edifice displacement are generally of the order of $10^{-7} \mathrm{~s}^{-1}$ or lower: for example, as estimated from borehole strainmeters in Linde et al. (1993), or from spaceborne interferometry in Massonnet et al. (1995). However, strain and strain rates are undoubtedly highly variable throughout active volcanic systems. The chosen strain rate for these experiments (the international standard in rock mechanics; Kovari et al., 1983; Ulusay and Hudson, 2007) is comparable to shear rates inferred to occur along conduit margins by Rust et al. (2003). Similarly, Cashman et al. (2008) estimate strain rates of $3-8 \times 10^{-5} \mathrm{~s}^{-1}$ for the formation of fault gouge at Mount St. Helens (USA). Most importantly, a strain rate of $10^{-5} \mathrm{~s}^{-1}$ ensures that our samples are drained (i.e. the product of the Darcy timescale and the strain rate is $\ll 1$; Heap and Wadsworth, 2016).

Confining pressure and pore pressure were servo controlled throughout the experiments. During hydrostatic and nonhydrostatic loading, the response of the pore fluid pump reflects variations in pore volume (see Read et al., 1995), which - normalised to the initial sample volume - corresponds to the porosity change $\Delta \phi$. For a porous material, $\Delta \phi$ can be considered equal to the volumetric strain. Indeed, the response of the confining pressure pump provides an independent estimation of the volumetric strain, found to be in perfect agreement with the inferred $\Delta \phi$ (see Baud et al., 2014 , for details). When this differential $\Delta \phi$ is positive, it signifies dilation (an increase in porosity) and when it is negative, it indicates compaction (a decrease in porosity). Deformation was allowed to continue for different amounts of axial strain accumulation - sample shortening relative to its original length $\left(\varepsilon_{t}\right)$ - then they were unloaded. The strain recovered during the unloading phase is subtracted from the total axial strain $\varepsilon_{\mathrm{t}}$ to give the inelastic (non-recoverable) strain accrued by the sample $\left(\varepsilon_{\mathrm{i}}\right)$. Similarly, the elastic porosity change recovered during unloading is subtracted from the porosity change at $\varepsilon_{\mathrm{t}}$ to give the inelastic porosity change $\Delta \phi_{\mathrm{i}}$. Samples were vacuum-dried once again and gas permeability was remeasured. Samples were all deformed at room temperature. We note that in natural volcanic environments there may be some influence of temperature on rock strength (due, for instance, to the closure of cracks driven by thermal expansion). Nevertheless, a recent study by Heap et al. (2017) shows that the influence of temperature on the physical and mechanical properties of andesite may not be significant at temperatures below the glass transition $T_{\mathrm{g}}$. Importantly, this study showed that the failure mode and under- 


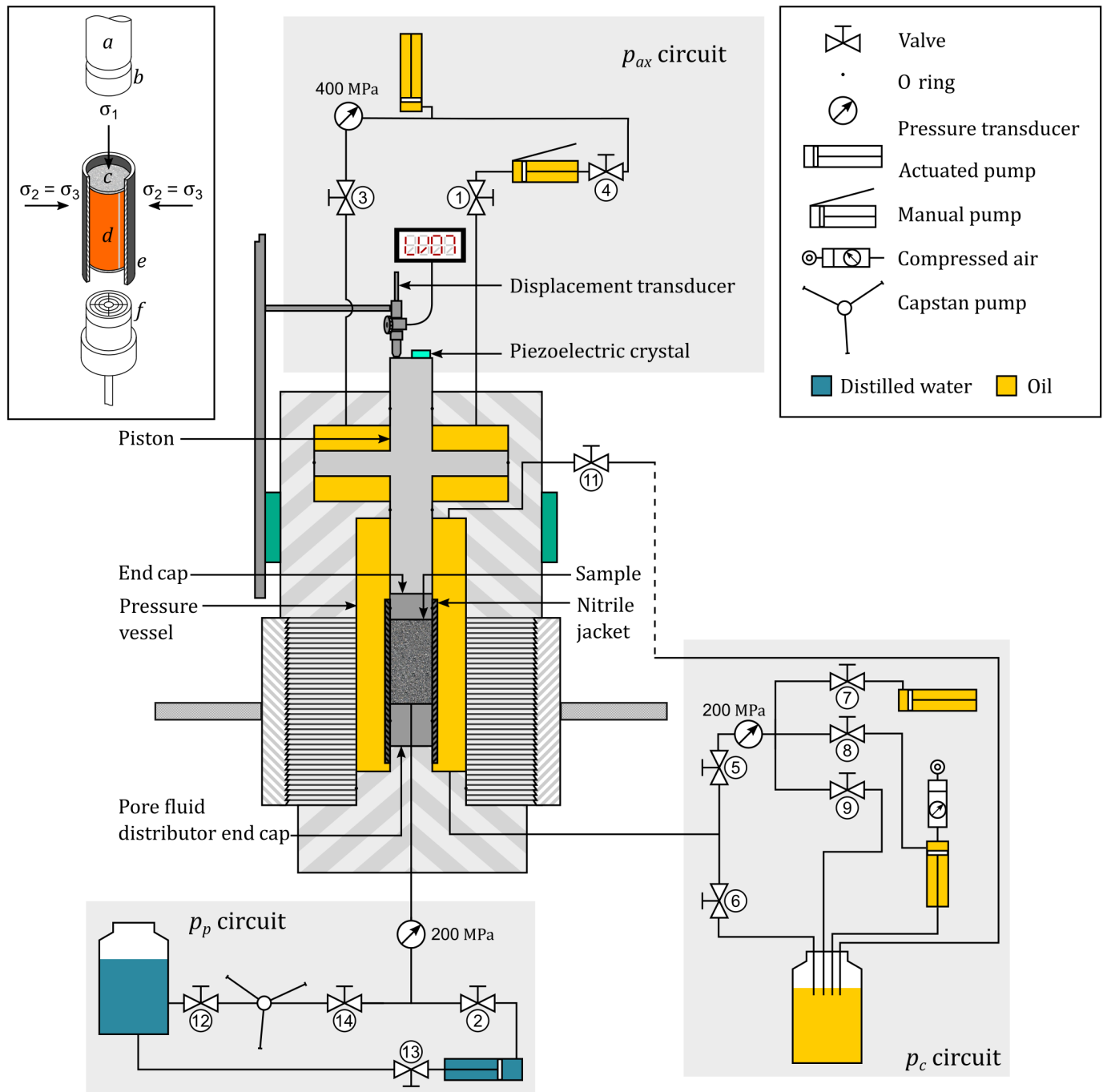

Figure 1. Schematic of triaxial deformation apparatus. Schematic of triaxial deformation apparatus, including confining pressure $p_{\mathrm{c}}$, pore pressure $p_{\mathrm{p}}$, and axial pressure $p_{\mathrm{ax}}$ circuits. Detail of sample assemblage is shown in the inset. (a) Axial piston; (b) blank end cap; (c) sample; (d) copper foil jacket; (e) nitrile jacket; (f) and pore fluid distributor end cap. Directions of major $\sigma_{1}$ and minor $\sigma_{3}$ principal stresses are as shown, such that $\sigma_{1}>\sigma_{2}=\sigma_{3}$. Not to scale. Numbered valves allow various parts of each circuit to be used at any given time.

lying microstructural mechanism driving ductile behaviour (cataclastic pore collapse) did not change below $T_{\mathrm{g}}$, which is itself largely restricted to the magma conduit and rock in the immediate vicinity. This is in agreement with previous studies by Vinciguerra et al. (2005) and Heap et al. (2014), both of which noted only negligible changes in microcrack density and porosity after thermally stressing volcanic materials. These authors attribute this phenomenon to the high initial crack density resulting from the complex thermal histories of volcanic rocks.

\subsection{Post-deformation permeability}

It has been shown in recent studies (e.g. Vinciguerra et al., 2005; Nara et al., 2011) that the permeability of fractured volcanic materials is influenced by the effective pressure under which it is measured: permeability tends to decrease with increasing effective pressure. As such, we acknowledge the limitation that post-deformation measurements do not represent the permeability under the deformation conditions sensu stricto. Nevertheless, we choose to measure permeability under the conditions described above for a host of reasons. Investigations towards determining the influence of effective pressure on properties (including permeability) other than rock strength indicate that their evolution with pressure may differ as a function of porosity, pore geometry, and other factors, which is to say that the effective pressure coefficient for a given rock property may not be the same as the BiotWillis coefficient $\alpha$ (Bernabé et al., 1986). Given the lack of constraint on the effective pressure effect for the permeabil- 
ity of volcanic rocks, permeability is measured at the lowest possible confining pressure (1 MPa, rather than at in situ pressures) and without imposing a differential stress, in order to allow comparison within and between sample sets (indeed, we compare our data with compiled literature data in Sect. 4.1). This procedure also avoids the potential for creep - a mechanism of time-dependent deformation whereby subcritical crack growth induces damage and possibly even failure at stresses below the short-term strength of the rock (e.g. Heap et al., 2011; Brantut et al., 2013) - as well as precluding other phenomena such as stress relaxation that may arise when measuring permeability under a differential stress.

Measuring permeability requires that the sample dimensions, specifically length and cross-sectional area, are well constrained. Prior to initial measurements of permeability, sample dimensions are measured accurately using digital callipers. However, samples are often barrelled and thus noncylindrical after mechanical deformation, making their mean radii nontrivial to determine. Assuming that the solid volume $V_{\mathrm{s}}$ remains constant throughout deformation, then the postdeformation volume is equal to the sum of solid volume, the initial pore volume, and the pore volume change after deformation. The post-deformation cross-sectional area $A_{\text {post }}$ can therefore be determined such that

$$
A_{\text {post }}=\underbrace{\left[\frac{V_{\mathrm{s}}}{1-\left(\phi+\Delta \phi_{\mathrm{i}}\right)}\right]}_{V_{\text {post }}} \times\left[\frac{1}{l_{\text {post }}}\right] \text {, }
$$

where $V_{\text {post }}$ is the post-deformation volume and $l_{\text {post }}$ is the mean sample length after deformation.

\section{Results}

Table 2 gives the deformation conditions ( $p_{\text {eff }}, \varepsilon_{\mathrm{t}}, \varepsilon_{\mathrm{i}}$ ) for each test, as well as pre- and post-deformation values of porosity and permeability. Mechanical data for all experiments performed under a range of effective pressures to differing amounts of strain - are shown in Fig. 2a, plotted as differential stress against axial strain. In each case, the stress-strain curve is concave upwards in the initial phase of sample loading (1 in Fig. 2a inset), which is followed by a period of linear elastic behaviour (2). Beyond a critical stress state (3), termed $C^{*}$ (Wong et al., 1997), the sample no longer deforms poroelastically (i.e. additional differential stress causes inelastic compaction: this is known as shear-enhanced compaction). This threshold - the compactive yield stress - signals the onset of shear-enhanced compaction. Thereafter (4), the material may continue to accommodate approximately the same amount of stress, or accumulate additional stress (a phenomenon known as strain hardening), where the stressstrain curve tends upwards post-failure. In many of the samples, the stress-strain curve is variably interposed by stress drops. The compactant behaviour is illustrated in Fig. $2 \mathrm{~b}$ :
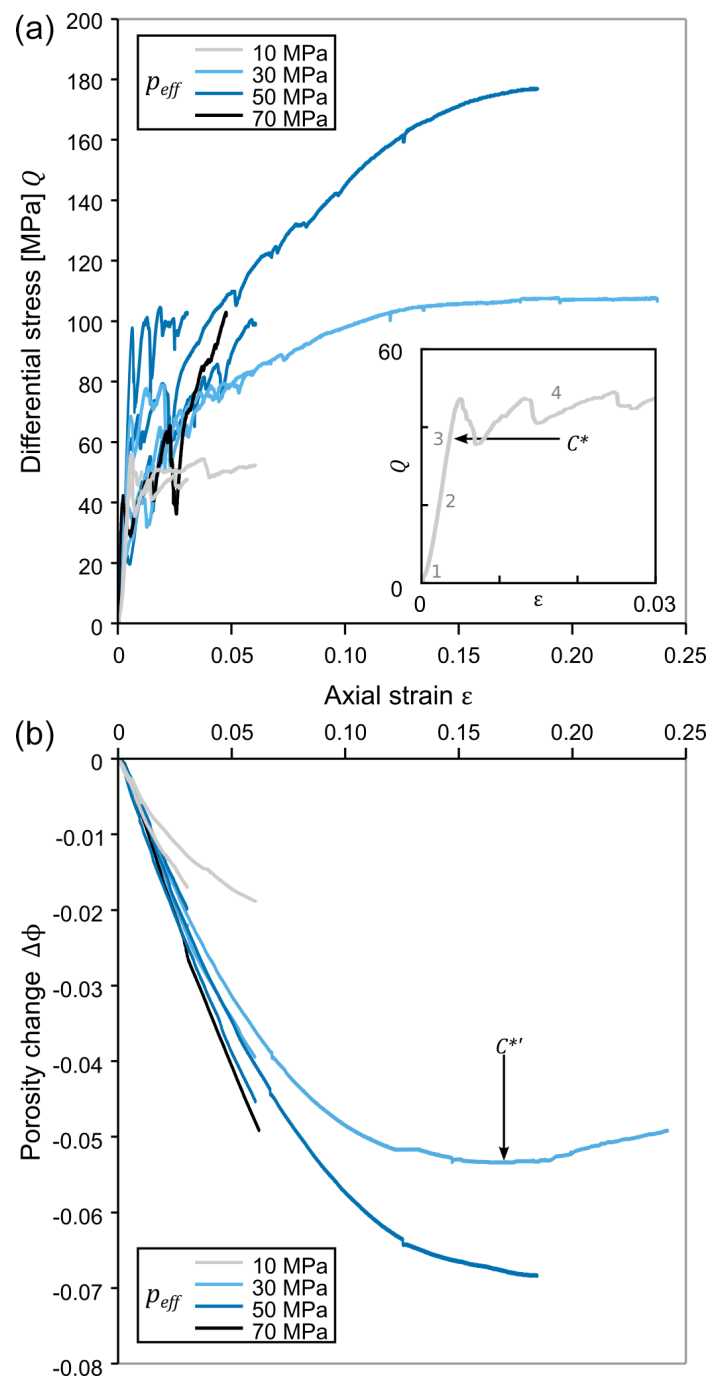

Figure 2. (a) Differential stress versus axial strain for all experiments. Inset shows a close-up of an experiment (sample LLB-7) highlighting different stages of deformation (refer to text for explanation). (b) Porosity change as a function of axial strain for all tests. Effective pressure at which deformation was performed is indicated by the line colour.

porosity tends to decrease monotonously with increasing axial strain, and the net porosity change is always negative. The trend of progressive compaction differs in one experiment (LLB-13): after a threshold strain the trajectory of the porosity change curve becomes positive (indicating dilation). This phenomenon is discussed in Sect. 4.2.

Figure 3a shows the inelastic change in sample porosity as a function of inelastic axial strain. The initial samples contained connected porosities ranging between 0.19 and 0.23 (see Table 2), which invariably decreased after accumulating strain in the ductile regime. The minimum porosity change was -0.005 , for a sample deformed under an effective pressure of $10 \mathrm{MPa}$ to an inelastic strain of 0.006 (a $0.6 \%$ reduc- 
tion in sample length). The maximum change in porosity was -0.074 , for a sample deformed at an effective pressure of $50 \mathrm{MPa}$ to an inelastic strain of 0.174 (i.e. a $17.4 \%$ reduction in sample length). For a given amount of inelastic strain, the volume of porosity lost through compaction is dependent on the effective pressure: more efficient compaction is evident at higher effective pressures. Figure $3 \mathrm{~b}$ shows post-deformation permeability $k_{\mathrm{e}}$ as a function of inelastic axial strain. At low strains $(<0.05)$, sample permeability tends to increase, from around $5 \times 10^{-13}$ to as high as $3.71 \times 10^{-12} \mathrm{~m}^{2}$ (almost 1 order of magnitude). This behaviour overlies a general trend of permeability decrease with increasing strain: at higher strains $(0.06-0.24)$ permeability can decrease relative to its original value by as much as 2 orders of magnitude. The largest decrease (sample LLB-13) was from $4.84 \times 10^{-12}$ to $5.51 \times 10^{-14} \mathrm{~m}^{2}$ after an inelastic strain accumulation of 0.233 .

\section{Discussion}

\subsection{Microstructural controls on permeability evolution}

The underlying micromechanical mechanism driving inelastic compaction in volcanic rocks has been shown to be cataclastic pore collapse (Zhu et al., 2011; Heap et al., 2015a; Zhu et al., 2016). Figure 4 illustrates this process by showing images of an intact and a deformed sample. Figure 4a is a backscattered scanning electron microscope image of an as-collected sample of LLB andesite, whereas the images in Fig. $4 \mathrm{~b}$ and c (from the same sample suite) are of a samples that has accumulated high strain $(>0.20)$ under an effective pressure of $30 \mathrm{MPa}$. The undeformed sample (Fig. 4a) is pervasively microcracked, with highly amoeboid pores ranging from $<10$ to around $80 \mu \mathrm{m}$ in diameter. Cataclastic pore collapse involves intense microcracking, which develops in a concentric damage zone around a pore. As the process of cataclasis - progressive fracturing and comminution - continues, fragments can spall into the void space, thus reducing porosity (Zhu et al., 2010). Figure $4 \mathrm{~b}$ clearly shows abundant fractures created during triaxial deformation, both within the groundmass and crystals. In many areas, fragments have been comminuted to the micron scale. In these samples, as observed in previous experimental studies of volcanic rock (Loaiza et al., 2012; Adelinet et al., 2013; Heap et al., 2015a), cataclastic pore collapse is localised in the form of bands traversing the sample.

The occurrence of compaction bands in andesite has been shown to correspond to periodic stress drops (Heap et al., 2015a), which are abundant in the mechanical data of Fig. 2a.

Our experimental data (Figs. $2 \mathrm{~b}$ and $3 \mathrm{a}$ ) show that cataclastic pore collapse progressively reduces the porosity of these andesites. If we assume that compaction is perfectly localised in our samples, we can consider a compaction band-bearing sample as a layered medium where the band
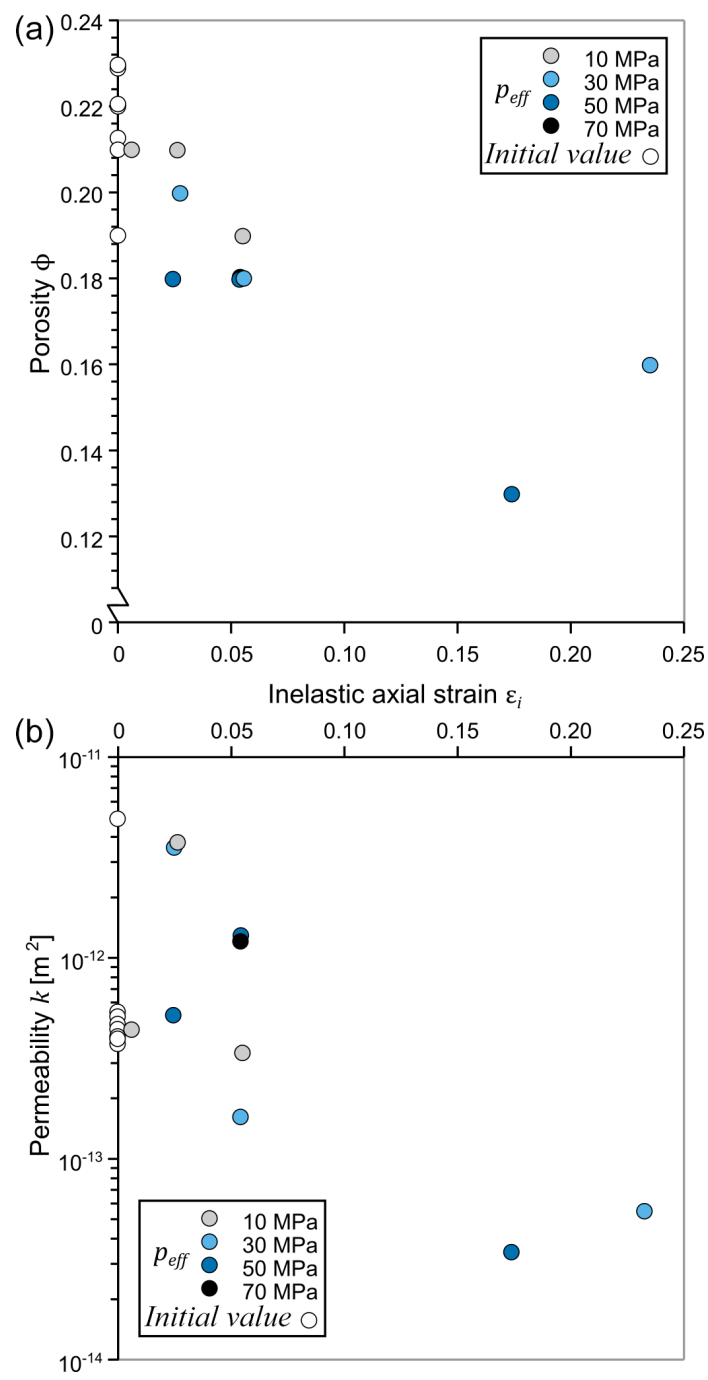

Figure 3. Change in physical properties after accumulating inelastic axial strain. (a) Pre- and post-deformation porosity (the latter calculated by $\phi+\Delta \phi_{\mathrm{i}}$ ) versus inelastic strain. Effective pressure is indicated by the symbol colour. (b) Pre- and post-deformation gas permeability as a function of the inelastic strain accumulated by each sample. Effective pressure is indicated by colour as in panel (a): note, however, that the value of $p_{\text {eff }}$ corresponds to deformation, whereas permeability was measured in each case at $p_{\text {eff }}=1 \mathrm{MPa}$.

of porosity $\phi_{\mathrm{b}}$ is embedded within an intact host with the initial rock properties (which is to say, a sample of porosity $\phi$ ). The intact material must have a pore volume $V_{1}^{\phi}$ of $\phi \times\left(l_{\text {intact }} \times A_{\text {post }}\right)$, where $l_{\text {intact }}$ is the overall length of the sample that is undamaged $\left(l_{\text {post }}-w_{\mathrm{b}}\right)$, where $w_{\mathrm{b}}$ is the width of the compaction band. The deformed sample contains a pore volume $V_{2}^{\phi}$ of $\phi+\Delta \phi_{\mathrm{i}} \times\left(l_{\text {post }} \times A_{\text {post }}\right)$. From this, we can relate the compaction band porosity $\phi_{\mathrm{b}}$ to the width of the compaction band:

$\phi_{\mathrm{b}}=\left[\frac{V_{2}^{\phi}-V_{1}^{\phi}}{A_{\text {post }}}\right] \times\left[\frac{1}{w_{\mathrm{b}}}\right]$. 
Table 2. Physical property data and deformation conditions for each sample. Samples were deformed under an effective pressure $p_{\text {eff }}$ until a total target strain $\varepsilon_{\mathrm{t}}$. Then they were unloaded to determine the inelastic strain $\varepsilon_{\mathrm{i}}$. Similarly, $\Delta \phi_{\mathrm{i}}$ indicates total porosity change after unloading. $p_{\mathrm{eff}}$ is determined by subtracting a constant $p_{\mathrm{p}}$ value of $10 \mathrm{MPa}$ from the confining pressure $p_{\mathrm{c}}$.

\begin{tabular}{lrrrrrrrrr}
\hline Sample & $\phi$ & $\phi_{\mathrm{u}}$ & $\begin{array}{r}p_{\text {eff }} \\
(\mathrm{MPa})\end{array}$ & $\varepsilon_{\mathrm{t}}$ & $\varepsilon_{\mathrm{i}}$ & $\Delta \phi_{\mathrm{i}}$ & $\phi+\Delta \phi_{\mathrm{i}}$ & $\begin{array}{r}k_{0} \\
\left(\mathrm{~m}^{2}\right)\end{array}$ & $\begin{array}{r}k_{\mathrm{e}} \\
\left(\mathrm{m}^{2}\right)\end{array}$ \\
\hline LLB-6 & 0.21 & 0.01 & 10 & 0.010 & 0.006 & -0.005 & 0.21 & $3.80 \times 10^{-13}$ & $4.35 \times 10^{-13}$ \\
LLB-7 & 0.23 & 0.01 & 10 & 0.030 & 0.026 & -0.017 & 0.21 & $4.83 \times 10^{-13}$ & $3.63 \times 10^{-12}$ \\
LLB-1 & 0.21 & $<0.01$ & 10 & 0.060 & 0.055 & -0.020 & 0.19 & $5.01 \times 10^{-13}$ & $3.29 \times 10^{-13}$ \\
LLB-10 & 0.22 & 0.01 & 30 & 0.030 & 0.025 & -0.021 & 0.20 & $5.24 \times 10^{-13}$ & $3.47 \times 10^{-12}$ \\
LLB-9 & 0.22 & 0.01 & 30 & 0.060 & 0.054 & -0.040 & 0.18 & $4.97 \times 10^{-13}$ & $1.55 \times 10^{-13}$ \\
LLB-13 & 0.22 & 0.01 & 30 & 0.240 & 0.233 & -0.055 & 0.16 & $4.84 \times 10^{-12}$ & $5.11 \times 10^{-14}$ \\
LLB-3 & 0.19 & 0.01 & 50 & 0.030 & 0.024 & -0.019 & 0.18 & $5.31 \times 10^{-13}$ & $5.09 \times 10^{-13}$ \\
LLB-11 & 0.22 & 0.01 & 50 & 0.060 & 0.054 & -0.045 & 0.18 & $5.03 \times 10^{-13}$ & $1.22 \times 10^{-12}$ \\
LLB-5 & 0.21 & 0.01 & 50 & 0.180 & 0.174 & -0.074 & 0.13 & $4.32 \times 10^{-13}$ & $3.17 \times 10^{-14}$ \\
LLB-14 & 0.23 & 0.01 & 70 & 0.060 & 0.054 & -0.048 & 0.18 & $4.70 \times 10^{-13}$ & $1.18 \times 10^{-12}$ \\
\hline
\end{tabular}

$\phi=$ connected porosity. $\phi_{\mathrm{u}}=$ unconnected porosity. $p_{\mathrm{eff}}=$ effective pressure. $\varepsilon_{\mathrm{t}}=$ target (total) axial strain. $\varepsilon_{\mathrm{i}}=$ inelastic axial strain. $\Delta \phi_{\mathrm{i}}=$ inelastic porosity change. $\phi+\Delta \phi_{\mathrm{i}}=$ post-deformation porosity. $k_{0}=$ initial permeability. $k_{\mathrm{e}}=$ post-deformation permeability.

Solutions for $\phi_{\mathrm{b}}$ and $w_{\mathrm{b}}$ are non-unique (moreover, a greater value of $w_{\mathrm{b}}$ could be a function of one wide band or a number of discrete, relatively thinner bands), but we can impose a lower bound on $\phi_{\mathrm{b}}$ of zero and an upper bound equal to the post-deformation porosity of the sample: $0 \leq$ $\phi_{\mathrm{b}}<\left(\phi+\Delta \phi_{\mathrm{i}}\right)$. Assuming that the compaction band porosity noted by Heap et al. (2015a) $(\sim 0.10)$ is typical for compacted andesite, then Fig. 4 yields compaction band widths of between 1.63 and $23.57 \mathrm{~mm}$ (i.e. between 4 and $70 \%$ of the overall sample length). We note that the lower end of this range is in line with the observations of Heap et al. (2015a).

We note that porosity loss is seemingly tied to the effective pressure under which compaction occurs (as observed in previous studies concerned with triaxial rock deformation, e.g. Wong et al., 1997; Baud et al., 2006; Heap et al., 2015a): for a given increment of inelastic strain, the porosity lost by a sample is greater at a higher effective pressure. This phenomenon is true both for total porosity change (Fig. 2b) and for inelastic porosity loss (Fig. 3a), which is to say that the inelastic compaction factor $\Delta \phi_{\mathrm{i}} / \varepsilon_{\mathrm{i}}$ always decreases as effective pressure increases (Baud et al., 2006).

While the mechanism of cataclastic pore collapse is governed by pore size (e.g. Zhu et al., 2010, 2011), it has also been demonstrated that the local stress field around a pore increases as a function of the incumbent confining pressure (Zhu et al., 2010). A study of fault gouge formation in sandstone (Engelder, 1974) shows that fault-zone fragments are smaller when generated at higher confining pressures, and a similar effect (albeit less pronounced) was noted by Kennedy et al. (2012), who investigated fault gouge formation in dacitic dome rock. It is reasonable to assume that cataclasis may become more efficient as the local stress field increases in line with the confining pressure; in turn, a finer distribution of fragments will more readily occlude the pores around which they develop. Whether a change in the mean fragment size generated during cataclastic pore collapse underlies the observed evolution of $\Delta \phi_{\mathrm{i}} / \varepsilon_{\mathrm{i}}$ remains open to a targeted microstructural study. Nevertheless, we can examine Fig. 4 to glean an idea of the effect of $\phi_{\mathrm{b}}$ and $w_{\mathrm{b}}$ at different effective pressures and axial strains.

Figure 5 shows the calculated $w_{\mathrm{b}}$ for our experimental data as a function of inelastic axial strain. Values of $w_{\mathrm{b}}$ are calculated using Fig. 4, using values of $\phi_{\mathrm{b}}$ of $0.20,0.15,0.10$, and 0.05 . At relatively higher imposed values of $\phi_{\mathrm{b}}(0.20$ and 0.15 ; Fig. 5a, b), many of the resulting values of $w_{\mathrm{b}} / l$ are non-physical (i.e. $w_{\mathrm{b}} / l \ngtr 0$ or $w_{\mathrm{b}} / l \nless 1$ ). However, at lower imposed values of $\phi_{\mathrm{b}}(0.10$ and 0.05 ; Fig. $5 \mathrm{c}, \mathrm{d})$, values fall between 0 and 1 . Moreover, there appears to be a systematic effect of $p_{\text {eff }}$, with deformation under relatively higher effective pressure yielding a higher ratio of $w_{\mathrm{b}} / l$ - hence, a thicker compaction band - for any given amount of inelastic axial strain accumulation.

As would be expected (e.g. Zhu and Wong, 1997), permeability reduction follows the same general trend (Fig. 3b) as porosity reduction (Fig. 3a), with samples accumulating high strains showing a correspondingly large reduction in permeability. Notably, there appears to be an influence of the effective pressure under which the sample was deformed and the change in permeability for a given increment of axial strain. A difference in measured post-deformation permeability $k_{\mathrm{e}}$ may be due to (1) a variation in characteristic grain size or (2) a variation in the thickness of compaction localisation features with respect to the sample length, as described above. Moreover, one may imagine that these two factors (characteristic grain size, band thickness) operate in tandem to reduce permeability as effective pressure increases. To test this theory, we again model the deformed samples as a layered medium, such that discrete bands of uniform permeability $k_{\mathrm{b}}$ and thickness $w_{\mathrm{b}}$ are embedded in a medium of permeability $k_{0}$ (see Fig. 6a). A similar approach was previ- 

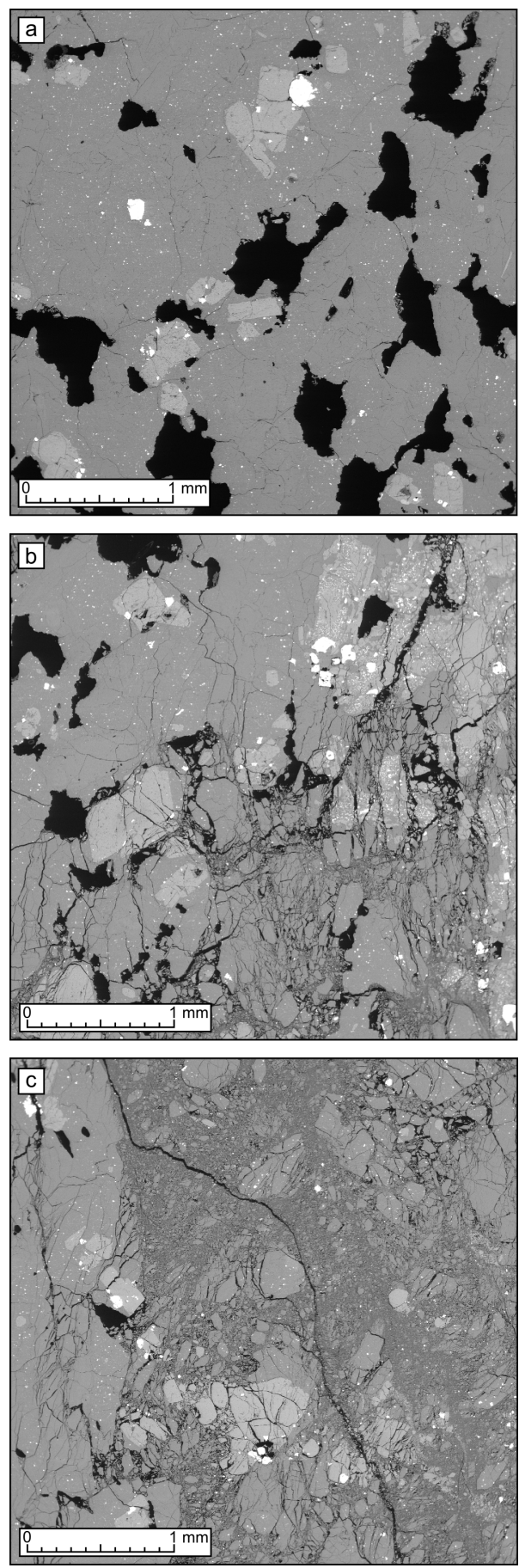

Figure 4. Backscattered scanning electron microscope images of LLB andesite, showing as-collected (a) and post-deformation (bc) microstructure. Void space appears as black. Dense (metal-rich) phenocrysts appear as white or light grey within a darker grey groundmass. Both (b) and (c) are images of LLB-13, which was taken to beyond both $C^{*}$ and $C^{* \prime}$. Cataclastic pore collapse associated with shear-enhanced compaction is shown in (b), while (c) shows part of the dilatant shear zone marking the transition from shear-enhanced compaction to dilation. ously adopted by Vajdova et al. (2004) and Baud et al. (2012) to model the permeability of sandstones containing experimentally induced compaction bands. Fluid flow through this simplified geometry may then be modelled by assuming conservation of mass (e.g. Freeze and Cherry, 1979), such that

$k_{\mathrm{e}}=k_{0} \times\left[\left(\frac{w_{\mathrm{b}}}{l}\right)\left(\frac{k_{0}}{k_{\mathrm{b}}}-1\right)+1\right]^{-1}$.

Variables $k_{\mathrm{e}}, k_{0}$, and $l$ are already constrained, allowing us to solve for combinations of $w_{\mathrm{b}}$ and $k_{\mathrm{b}}$. If we assume that a compaction band comprises a granular bed (Fig. 6a inset), we can relate its permeability $k_{\mathrm{b}}$ to surface area $s$ in the following manner after Martys et al. (1994), who determined a universal scaling of permeability of a system of packed spheres:

$k_{\mathrm{b}}=\frac{2\left(1-\phi^{*}\right)}{s^{2}} \phi^{* f}$,

where $\phi^{*}=\phi_{\mathrm{b}}-\phi_{c}$ and $f=4.2$ (the value of $f$ is thought to be related to the initial grain geometry; Wadsworth et al., 2016). $\phi_{c}$ represents the percolation threshold, taken here as 0.03 . Note that the characteristic porosity is taken as the porosity within a compaction band $\phi_{\mathrm{b}}$ (i.e. the porosity of the granular layer with permeability $k_{\mathrm{b}}$ and width $w_{\mathrm{b}}$ ). In turn, we can relate $s$ to a characteristic grain size (e.g. Wadsworth et al., 2016):

$s(r)=\frac{3\left(1-\phi_{\mathrm{b}}\right)}{r}$,

where $r$ is the monodisperse particle radius. Note that in reality, the porosities assumed within the compaction bands here are not compatible with a monodisperse packing of spheres. Nevertheless, this greatly simplified approach gives an indication of the relative influence of the difference constituent parameters $r, \phi_{\mathrm{b}}$, and $w_{\mathrm{b}}$.

The assumed geometry is illustrated in Fig. 6a, including the corresponding values of permeability and porosity for each layer. Figure $6 \mathrm{~b}$ highlights the effects of changing either the characteristic particle (i.e. grain) radius or the compaction band porosity. Notably - for a given porosity - a change in particle radius of 1 order of magnitude results in a change in compaction band permeability of 2 orders of magnitude. At relatively high initial porosities, a reduction in porosity by a given volume (for example, from 0.20 to 0.15 ) has little influence on $k_{\mathrm{b}}$. Conversely, when the porosity is low, a change in porosity of the same absolute volume (for example, from 0.10 to 0.05 ) exerts a much greater influence over $k_{\mathrm{b}}$ (in this case, a reduction by over 2 orders of magnitude). However, the bulk sample permeability (the equivalent permeability) depends not only on the porosity of the compaction band but also its width. Figure $6 \mathrm{c}-\mathrm{f}$ show the equivalent permeability for different values of $\phi_{\mathrm{b}}$ for changing values of $w_{\mathrm{b}} / l$ : the ratio of the band width to the overall length of the sample. Curves are modelled by combining Equations (5), (6), and (7), using the particle radii $r$ (noted on each figure panel) 


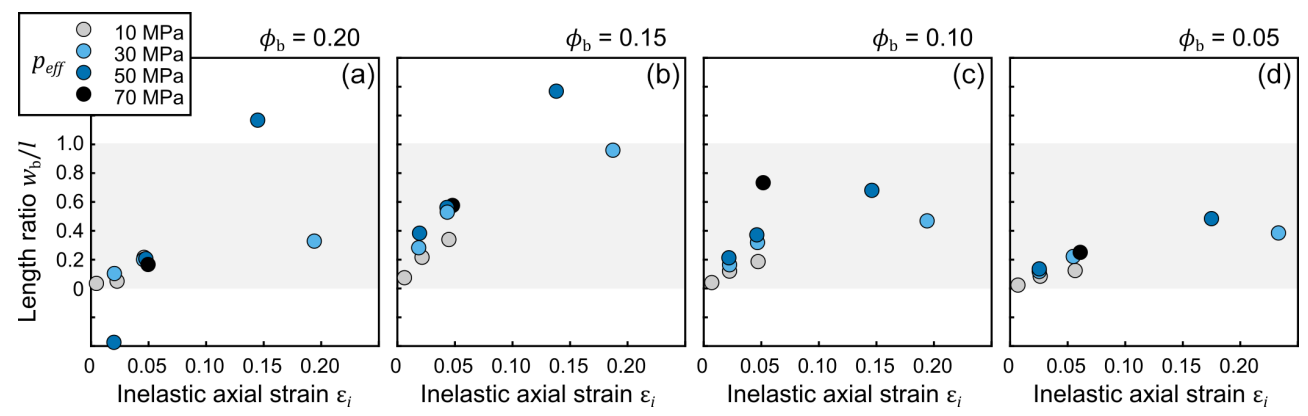

Figure 5. Calculated sample length ratio $w_{\mathrm{b}} / l$ as a function of inelastic axial strain accumulation $\varepsilon_{\mathrm{i}}$. Values of $w_{\mathrm{b}}$ calculated from Eq. (4) using values of compaction band porosity of $\phi_{\mathrm{b}}=0.20(\mathbf{a}), \phi_{\mathrm{b}}=0.15(\mathbf{b}), \phi_{\mathrm{b}}=0.10(\mathbf{c})$, and $\phi_{\mathrm{b}}=0.05(\mathbf{d})$. Shaded area indicates range of physical values of $w_{\mathrm{b}} / l$.

and a value of $k_{0}=5.0 \times 10^{-13} \mathrm{~m}^{2}$. As there are multiple non-unique solutions for $\phi_{\mathrm{b}}$ and $w_{\mathrm{b}}$, we show model results for a range of potential $\phi_{\mathrm{b}}$ values in Fig. 6c-f.

Evidently, the variation in our experimental data (for example, the difference between $k_{\mathrm{e}}$ of samples deformed under different effective pressures) is not explained by a systematic evolution of $r$. This suggests that while $k_{\mathrm{b}}$ is very sensitive to the characteristic grain radius, the tradeoff between $\phi_{\mathrm{b}}$ and $w_{\mathrm{b}}$ is more important in controlling the bulk sample permeability $\left(k_{\mathrm{e}}\right)$. Importantly, however, idealising the geometry of a compaction band in terms of a monodisperse particle size distribution cannot accurately represent its complex porous network. More accurate values of $\phi_{\mathrm{b}}$ and $s$ (and hence, a better prediction of $k_{\mathrm{b}}$ and $k_{\mathrm{e}}$ ) may be achieved by adopting a polydisperse particle size distribution or by imposing a nonspherical characteristic particle shape, for example.

An evident weakness of employing the simple layered medium model outlined above is that we assume that the only operative mechanism is porosity- and permeability-reducing. However, at low strains, there is no one-to-one relationship between permeability and porosity after deformation. Rather, permeability tends to increase moderately at inelastic axial strains less than around 0.05 (i.e. a 5\% shortening in sample length): while initial values of permeability tended to be around $5 \times 10^{-13} \mathrm{~m}^{2}$, the measured post-deformation permeability was often greater than $10^{-12} \mathrm{~m}^{2}$ after accumulating a small amount of axial strain (Table 2). A similar phenomenon was also observed by Loaiza et al. (2012), who noted that permeability of Açores trachyandesite increased beyond a critical stress state during hydrostatic pressurisation. This critical stress - known as $P^{*}$ (Zhang et al., 1990) signals the onset of lithostatic inelastic compaction; Loaiza et al. (2012) show that stress-induced cracks coalesce between collapsed pores during hydrostatic compaction, improving connectivity and, in turn, increasing permeability. Prior to deformation, the samples of porous andesite used in our experiments - LLB - contained an isolated porosity of 0.01 , on average (Table 2).
Similar to the mechanism posited by Loaiza et al. (2012), we suggest that distributed microcracking during the initial stages of ductile deformation serves to interconnect this isolated porosity, creating efficient pathways for fluid flow. The mechanical data of all the experiments (Fig. 1a) exhibit intermittent stress drops - even in the instances where permeability was observed to increase relative to the initial value - which suggests that compaction localisation in these andesites does not necessarily equate to the formation of an effective barrier to fluid flow. Loaiza et al. (2012), Adelinet et al. (2013), Heap et al. (2015a), and Heap et al. (2016) each examine microstructure of compaction bands formed in porous volcanic rocks (trachyandesite, basalt, andesite, and dacite, respectively). In all cases, the bands are irregular in shape and thickness but do not necessarily constitute a contiguous surface of collapse pores (i.e. a layer of reduced porosity). This is supported by the results from a recent study by Baud et al. (2015), which examined compaction bandbearing sandstones using X-ray-computed tomography. The authors show that when compaction bands are formed in a rock with porosity clusters, their path is more tortuous than in material with homogeneous porosity; consequently, the bands do not comprise efficient permeability barriers in three dimensions. Notably, the porosity of the andesites deformed in our study exhibit marked heterogeneity in terms of porosity, pore shape, and pore size distribution (Fig. 4a). The characteristic tortuosity of compaction bands formed in heterogeneous volcanic material - and the fact that the reduction in porosity relative to the host sample is remarkably less than observed in sandstones (Baud et al., 2012) - may explain the lack of an obvious observed influence on sample permeability in this study. Thus, counter-intuitively, small amounts of stress-induced compaction may actually increase permeability in volcanic materials. At higher strains however, this effect is overtaken by the global reduction in sample porosity, which serves to decrease the mean flow path aperture and forces fluids to travel through more tortuous routes. 

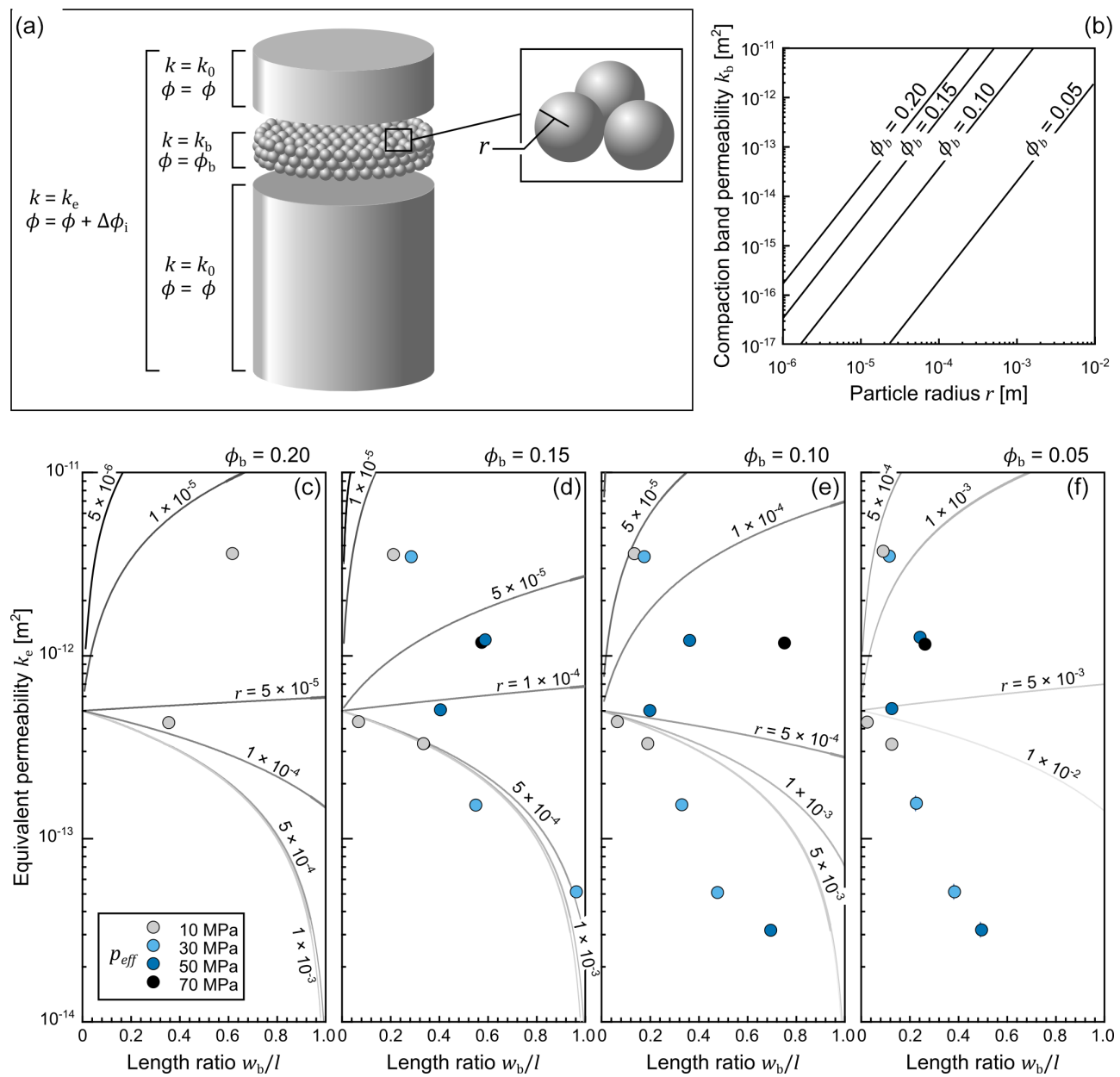

Figure 6. Model geometry and results. (a) Deformed sample may be thought of as a granular bed (with permeability $k_{\mathrm{b}}$ and porosity $\phi_{\mathrm{b}}$ ) within a sample matrix, with permeability $k_{0}$ and porosity $\phi+\Delta \phi_{\mathrm{i}}$. Inset highlights the characteristic grain radius that governs surface area (Eq. 7). (b) The permeability of a compaction band composed of packed spheres as a function of sphere radius and bed porosity. Note that in reality, porosities $<0.26$ would require a polydisperse packing of spheres or a granular bed composed of non-spherical grains. (c-f) Modelled equivalent permeability $k_{\mathrm{e}}$ of a compaction band-bearing sample, plotted against the ratio of compaction band width relative to the overall sample length $\left(w_{\mathrm{b}} / l\right)$, for compaction band porosities of $\phi_{\mathrm{b}}=0.20(\mathbf{c}), \phi_{\mathrm{b}}=0.15(\mathbf{d}), \phi_{\mathrm{b}}=0.10(\mathbf{e})$, and $\phi_{\mathrm{b}}=0.05(\mathbf{f})$. Also plotted are data from this study (Table 2), where values of $w_{\mathrm{b}}$ are calculated after Eq. (4). Note that of the $10 k_{\mathrm{e}}, w_{\mathrm{b}} / l$ data pairs from this study, not all are plotted on each of the panels (c) to (f). This is because certain combinations of $\phi_{\mathrm{b}}$ and $w_{\mathrm{b}}$ yield non-physical values (Eq. 4). Refer to text for further discussion.

\subsection{A limit to compaction and permeability reduction}

Porosity exerts a first-order control on the brittle-ductile transition of porous rocks (e.g. Wong and Baud, 2012). High porosity fosters ductile behaviour in response to an applied differential stress, whereas dilatant brittle behaviour is anticipated in low-porosity materials. If a high-porosity volcanic rock undergoes progressive compaction, it will eventually achieve a porosity low enough to respond in a dilatant fashion. The critical stress state at this transition, known as $C^{* \prime}$, has been previously described in sedimentary materials (e.g. Schock et al., 1973; Baud et al., 2000; Vajdova et al., 2004; Baud et al., 2006; Regnet et al., 2015) and recently in andesite from Volcán de Colima (Heap et al., 2015a). As antici- pated, beyond a threshold stress-strain accumulation, sample LLB-13 exhibits a transition from compactant deformation to dilatant behaviour (highlighted by the arrow in Fig. 1b). In volcanic rock - at the sample scale - this is characterised by significant shortening and barrelling of the sample (a consequence of the high strains required to achieve and exceed $C^{* \prime}$ ) and the generation of a dilatant shear zone (Heap et al., 2015a), characteristically similar to highly strained fault zones observed in volcanic rock (Farquharson et al., 2016b). Figure 4 illustrates these separate mechanisms, with evidence of cataclastic pore collapse being shown in Fig. $4 \mathrm{~b}$ and the shear zone shown in detail in Fig. 4c. As well as inhibiting net compaction, the transition to dilatant behaviour after a critical stress threshold may well constitute a limit to perme- 
ability reduction. Indeed, Regnet et al. (2015) observed that the permeability of an oolitic limestone increased when deformed triaxially beyond $C^{* \prime}$ to a level greater than its original value. This suggests that the volumetric increase associated with continued deformation after this critical stress state is linked to the generation of an efficient flow path for transmitted fluids. The concept of a limit to porosity and permeability reduction is supported by compiled data shown in Fig. 7 and suggests that for a volcanic rock of given initial porosity, there is a limited range of strain-induced subsolidus $k-\phi$ states in which it can exist: one cannot compact indefinitely without promoting dilatant mechanisms.

Figure 7 compiles data from this study with those of Farquharson et al. (2016b) and Heap et al. (2015a). Farquharson et al. (2016b) performed triaxial experiments on lowand intermediate-porosity volcanic rocks (basalt from Mount Etna, Italy, and andesites from Volcán de Colima and $\mathrm{Ku}-$ mamoto, Japan), exploring the evolution of physical properties as a function of stress-induced dilation. Heap et al. (2015a) performed compaction experiments comparable to those described in this study, with pre- and post-deformation permeability being assessed for two samples of San Antonio (C8) andesite from Volcán de Colima. Notably, data for porosity (Fig. 7a) and permeability (Fig. 7b) of all samples tend to converge towards intermediate values with ongoing strain accumulation. For this set of samples, an initial porosity range of $0.05-0.23$ reduces to values between 0.07 and 0.19 after an axial strain of 0.05 , and thereafter to a range of 0.08 to 0.17 after an axial strain of 0.10 . A similar trend can be observed in the permeability data, albeit with appreciably more scatter. Assuming that stress-induced fracture and compaction are common in active volcanic environments, this phenomenon of convergence towards intermediate values (i.e. $0.10 \leq \phi \leq 0.20 ; 10^{-14} \leq k \leq 10^{-13} \mathrm{~m}^{2}$ ) might partially explain why the modal porosity of large datasets of edifice-forming material tends to fall between 0.10 and 0.20 (e.g. Mueller et al., 2011; Bernard et al., 2015; Farquharson et al., 2015; Lavallée et al., 2017).

\subsection{Implications for volcanology}

Our experimental results highlight that permeability evolution during stress-induced compaction may be complex, but an overarching trend of decreasing permeability is anticipated, especially if volcanic rock can compact to relatively high amounts of strain (i.e. >0.06). This section examines these results in a broader context: if we can expect permeability of edifice-forming rocks to vary due to porosity, effective pressure and stress, then what influence does this have on volcanic activity?

Due to different histories of degassing, ascent, and eruption processes for different volcanic ejecta and effusive products (e.g. Mueller et al., 2011), heterogeneous edifice porosity may arise over time. Volcán Rincón de la Vieja, for example, exhibits contrasting flank compositions as tephra is predominantly deposited on the western side due to the prevailing trade winds, whereas dense lava flows have been historically concentrated to the north and south (Kempter et al., 1996). Similarly, Volcán Casita (Nicaragua) is composed primarily of pyroclastic units on the southwest side (again a consequence of the prevailing wind direction), whilst the majority of relatively denser lava flows extend to the east because of an asymmetric crater morphology (van Wyk de Vries et al., 2000). Indeed, geophysical surveys of active and historically active volcanoes indicate that significant variations in density (and hence, porosity) may be a common feature of stratovolcano edifices worldwide. For example, Tiede et al. (2005) use gravimetric inversion to explore edifice density at Gunung Merapi, identifying a relatively low-density unit on the western flank. These authors calculate an average porosity of 0.21 for this unit: a high value compared to the average edifice porosity of around 0.15 determined by Setiawan (2002) and the range of 0.05 to 0.10 estimated by Commer et al. (2005) for the region directly below the Merapi summit. These values are generally consistent with measured laboratory values of porosity for Merapi samples (Le Pennec et al., 2001; Kushnir et al., 2016). Similar contrasts in density have been inferred from gravimetric studies of several other volcanic regions such as Mauna Loa, Hawai'i (Zucca et al., 1982), Campi Flegrei, Italy (Cubellis et al., 1995), PuyehueCordón Caulle, Chile (Sepúlveda et al., 2005), and in the Central Volcanic Complex of Tenerife, Spain (Gottsmann et al., 2008).

In agreement with previous experimental studies (Loaiza et al., 2012; Adelinet et al., 2013; Zhu et al., 2016), the data presented here show that relatively porous edifice rock is prone to compact, even under low effective pressure (i.e. at shallow depths), whereas Heap et al. (2015a) and Farquharson et al. (2016b), for example, show that volcanic rocks with a low initial porosity will preferentially dilate when subject to stress. Thus, one or the other of these two processes will be dominant in different regions of a volcanic edifice. If we take Gunung Merapi as an example, the relatively porous western flank should compact - if subject to an imposed differential stress - in the shallow edifice. Conversely, the denser regions will fracture near the surface but facilitate compaction at depth by increasing the overlying lithostatic pressure for a given depth (i.e. the effective confining pressure). Accordingly, permeability reduction should occur over time and with increased strain in the western portion of the edifice, whereas permeability of the other flanks should increase. This is in agreement with the broad trend of outgassing observed at Gunung Merapi: quiescent outgassing occurs through and around the central vent, as well as through fumarole fields located to the east, southeast, and south of the main crater (Le Cloarec et al., 2003), while fumarole fields are absent to the west of the crater.

This field evidence underscores the importance of the spatial distribution of edifice rock with differing physical and mechanical properties in terms of the evolution of permeabil- 

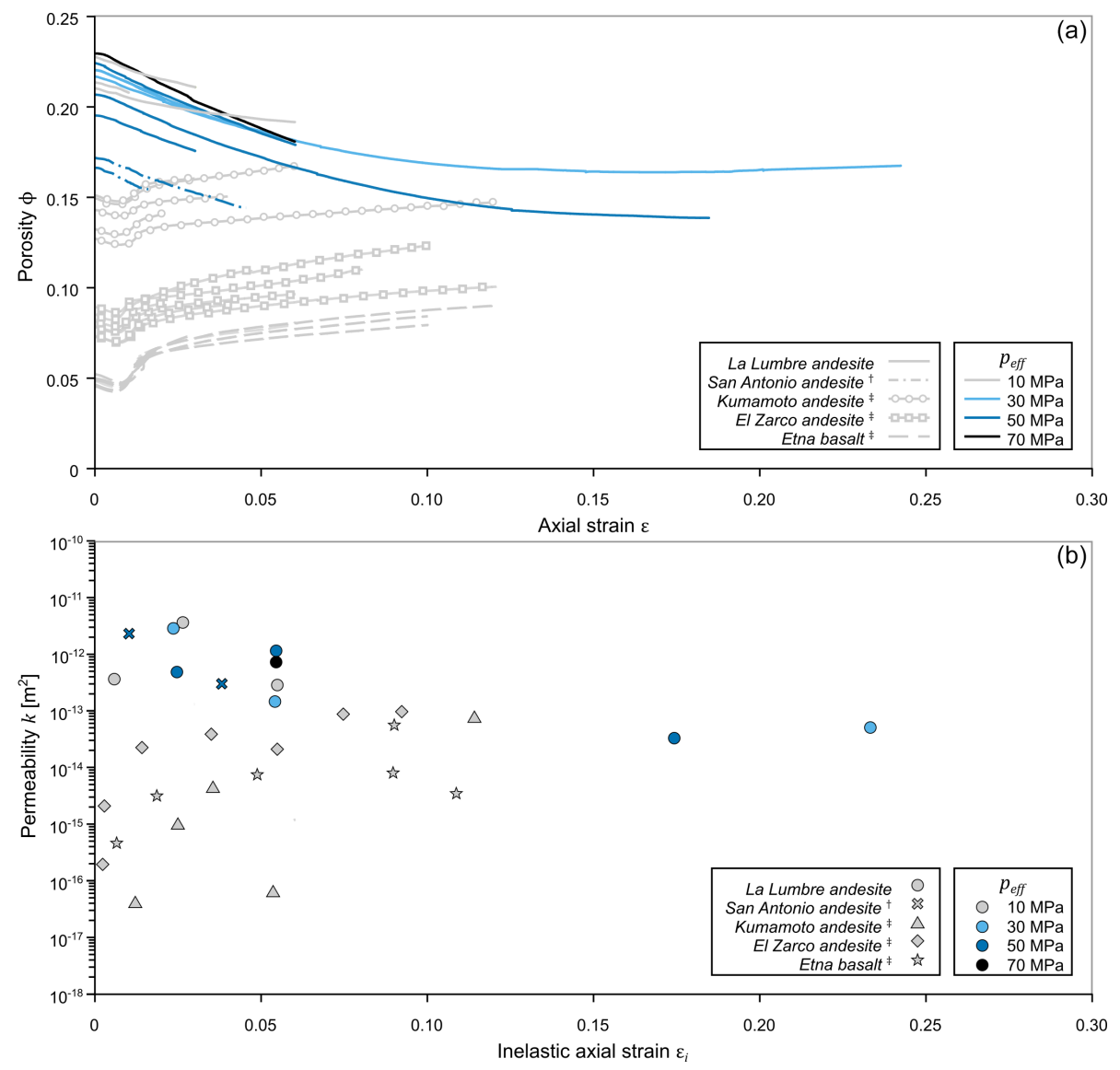

Figure 7. Compiled porosity and permeability data for triaxially deformed volcanic rocks. $\dagger$ Heap et al. (2015a); $\ddagger$ Farquharson et al. (2016b). (a) Porosity during deformation, calculated by summing the porosity change $\Delta \phi$ and the initial sample porosity $\phi$. Samples are distinguished by line and effective pressure by colour. (b) Permeability measured the post-deformation as a function of inelastic strain. Samples are distinguished by symbol and effective pressure by colour.

ity and outgassing routes in volcanic systems. Highly porous edifice rock may constitute an effective means of passive outgassing during periods of eruptive quiescence; when subject to stress, however - for example as a result of shallow fluid migration (e.g. Denlinger and Hoblitt, 1999; Clarke et al., 2007) or deep-seated magma chamber deformation (e.g. Melnik and Sparks, 2005; Wadge et al., 2006) - its permeability will tend to decrease. In turn, this may hinder outgassing and promote explosive activity. However, as our data show (Fig. 3b), low amounts of inelastic strain may actually increase permeability, possibly by connecting isolated porosity. In this case, stress-induced compaction may yield a temporary increase in permeability and flank outgassing, belying a longer-term trend of permeability reduction. This implies that the spatial and temporal distribution of fumaroles and the vigour with which they outgas may contain important information regarding subsurface strain accumulation: in a quiescent system, changes in the volume of passive outgassing of magmatic gas species may reflect stress-induced compaction, portending a build-up of pressure and potential explosive activity.

\section{Conclusions}

Volcanic rock of relatively high porosity (i.e. $>0.20$ ) can compact as a function of inelastic strain accumulation. We performed a series of triaxial deformation experiments on a suite of porous andesite in order to explore the influence of stress-induced compaction on porosity and permeability evolution. The efficiency of compaction was found to be a function of the effective pressure under which deformation occurred: at higher effective pressure, a greater volume of porosity was lost for any given amount of inelastic strain, reflecting the reduction in the inelastic compaction factor as a function of increasing effective pressure. We suggest that the associated underlying physical mechanism is progressively more efficient pore occlusion through cataclastic pore collapse at higher confining pressures, possibly due to enhanced comminution. By modelling a simple sample geometry where a compaction band is represented by a packed granular bed, we show that the permeability reduction within a discrete compaction band is sensitive to the characteristic grain size. The effect of the porosity of a compaction band 
has a variable influence on its permeability, with changes in band porosity becoming ever more important as porosity decreases. However, the overall trade-off between the width and porosity of a compaction band are far more important that grain size in controlling fluid flow throughout the bulk of a sample. At low strains $(<0.05)$, compaction tends to result in a moderate increase in permeability (not accounted for in our model), which we suggest is a result of increased pore connectivity due to distributed microcracking. This effect is outweighed by progressive compaction at higher strains, resulting in a general trend of decreasing permeability with ongoing inelastic compaction. There exists a physical limit to compaction, which we suggest is echoed in a limit to the potential for permeability reduction in a deforming sample. Compiled data show that at high strain, porosity and permeability tend to converge towards intermediate values (i.e. 0.10 $\leq \phi \leq 0.20 ; 10^{-14} \leq k \leq 10^{-13} \mathrm{~m}^{2}$ ). Field evidence from the literature emphasises the importance of understanding the physical and mechanical properties of rock in active volcanic environments, in particular the evolution in a rock's capacity to effectively transmit magmatic volatiles.

Data availability. Data are presented in Tables 1 and 2 in the text or are available on request to the corresponding author. 


\section{Appendix A: Measuring permeability}

The constitutive equation governing fluid transport in porous and granular media was originally derived from experiments performed by Henry Darcy in the 1850s on the flow of water at different levels through sand. Since Darcy's work (1856), the theoretical framework of fluid transport - which is based on Newton's second law - has been well established and expanded, such that flow of gas through a porous medium may be given as

$Q_{\mathrm{v}}=\frac{-k A}{\mu} \frac{\left(p_{b}-p_{a}\right)}{l}$,

where $\mu$ is the fluid viscosity, $Q_{\mathrm{v}}$ is the volumetric flow rate, $A$ is the cross-sectional area available for flow, and $l$ is the distance over which fluid flow occurs (i.e. the sample length). In a fluid transport system, flow is driven towards the region of lowest potential energy. In the special case of horizontal flow, this may be described by a differential between a region of relatively high pressure $p_{b}$ to one of relatively lower pressure $p_{a}$ : a pressure differential or pressure drop $\nabla p$. Equation (A1) is valid for all porous media as long as flow is laminar (two cases of non-laminar flow are discussed hereafter). While this expression is sufficient for the case of laminar (or streamline) flow, when considering an ideal compressible gas measured under atmospheric conditions, it becomes convenient to present gas permeability $k_{\text {gas }}$ in the following manner (Klinkenberg, 1941; McPhee and Arthur, 1991):

$k_{\mathrm{gas}}=\frac{Q_{\mathrm{v}} \mu l \cdot p_{\mathrm{atm}}}{A \cdot \nabla p \bar{p}}$,

where $p_{\text {atm }}$ is the atmospheric pressure at which $Q_{\mathrm{v}}$ is measured, and the driving pressure is given as a product of the differential pressure $\nabla p$ and the mean pressure over the sample $\bar{p}$. The mean pressure $\bar{p}$ is determined by the upstream and downstream pressures $p_{b}$ and $p_{a}$ such that $\bar{p}=$ $\left(p_{b}+p_{a}\right) / 2$. Under ambient conditions, $p_{a}$ is equal to the atmospheric pressure $p_{\text {atm }}$, and $p_{b}$ is equal to $\nabla p+p_{\text {atm }}$. The mean pressure therefore simplifies to $\bar{p}=\left(\nabla p+2 p_{\text {atm }}\right) / 2$.

Herein, gas permeability was measured using a steadystate permeameter using the set-up described in Farquharson et al. (2016c). The apparatus is a commercial benchtop permeameter from Vinci Technologies, modified by incorporating interchangeable EL-FLOW volumetric mass flowmeters (from Bronkhorst) to measure the volumetric flow rate of gas at the downstream end of the experimental samples. Gas permeability was measured using nitrogen as the permeant (pore fluid). A confining pressure of $1 \mathrm{MPa}$ was applied radially to the sample in order to ensure that no leakage occurred along its margins during measurement. The sample was then left under this confining pressure for $1 \mathrm{~h}$ to allow for any necessary microstructural equilibrium. Gas would then be flowed through the sample, whilst the volumetric flow rate $Q_{\mathrm{v}}$ and the pressure differential $\nabla p$ across the sample were continuously monitored by means of a customised data acquisition system and a LabVIEW program written for this purpose.

The pressure of gas entering the sample could be adjusted using a regulator attached to the permeant gas bottle. By altering the flow of gas, a range of different values of $\nabla p$ were imposed across the samples (typically between 0.001 and $0.2 \mathrm{MPa}$ ). Once steady-state flow was achieved, the volumetric flow rate was noted. Thus, with knowledge of the gas viscosity and sample dimensions, permeability could be calculated using Eq. (A2). However, two scenarios make it necessary for post-measurement corrections to be applied to the calculated values due to inertial effects: flow turbulence or gas slippage.

\section{A1 Non-laminar flow 1: turbulence}

Forchheimer (1901) conducted fluid flow experiments through porous media, noting that the relationship between the pressure differential $\nabla p$ and the volumetric flow rate $Q_{\mathrm{v}}$ becomes nonlinear at high fluid velocities due to flow no longer being laminar. To account for this turbulence, an inertial term, here denoted $\iota$, must be introduced, such that

$\frac{1}{k_{\mathrm{fo}}}=\frac{1}{k_{\mathrm{gas}}}-\iota \cdot Q_{\mathrm{v}}$,

where $k_{\text {fo }}$ is the Forchheimer-corrected permeability value, and $k_{\text {gas }}$ is the as-measured value. In this scenario, the measured gas permeability would be lower than the true (corrected) permeability, as turbulence induces resistance to fluid flow.

\section{A2 Non-laminar flow 2: gas slippage}

In his seminal 1941 paper, Klinkenberg showed that as the characteristic pore size or aperture approaches the mean free path of the permeant gas - the distance travelled between consecutive molecular collisions - interactions between the gas molecules and the pore (or crack) walls serve to reduce resistance to flow. Simply put, during liquid laminar flow, the layer of molecules adjacent to the pore (or crack) walls is static. However, for gases this molecule layer has a nonzero velocity due to molecular diffusion (slip). This slippage results in a higher flow rate at any given pressure differential for a gas than a liquid. Accordingly, the permeability measured using a gas would be artificially higher than if determined using a liquid.

The relationship of Klinkenberg (1941) is incorporated thus

$k_{\mathrm{gas}}=k_{\mathrm{kl}}\left(1+\frac{b}{\bar{p}}\right)$,

where $k_{\text {gas }}$ is the as-measured permeability calculated from gas flow experiments (note that in cases where a Forchheimer 
correction has been applied as in Eq. A3, $k_{\text {gas }}$ is substituted by $k_{\text {fo }}$ in Eq. A4), $\bar{p}$ is the mean flow pressure of gas in the system, $b$ is the Klinkenberg parameter (which depends on both the gas used but also the pore structure), and $k_{\mathrm{kl}}$ is the Klinkenberg-corrected permeability value.

In the absence of inertial effects, plotting $Q_{\mathrm{v}}$ against the driving pressure (i.e. $\nabla p \bar{p}$ ) yields a linear relationship. Deviations from linear behaviour indicate that one or both of the inertial phenomena described above influence the calculated permeability. In practice, the corrected permeability can be calculated using the slope and intercept of graphs of $Q_{\mathrm{v}}$ against $k_{\text {gas }}^{-1}$, and $\bar{p}^{-1}$ against $k_{\mathrm{fo}}$. In the main body of the text measured permeability, corrected for turbulence and/or gas slippage when necessary, is always presented as $k$. Figure A1 shows example data from volcanic rocks, which exhibit laminar flow, turbulence, and gas slippage. The effects of inertial flow, especially in the case of gas slippage, tend to be slight, although non-negligible.

\section{A3 Permeability and experimental error}

Sources of error in the permeability measurements include the sample dimensions and the resolution of the pressure transducer and flowmeters. As mentioned, permeability is determined as a function of the $Q_{\mathrm{v}}-\nabla p \bar{p}$ curve, which is a series of points fit by a simple linear regression (when flow is laminar). The respective precision of the transducer and flowmeter is thus encompassed by the coefficient of determination of the regression line (i.e. its $r^{2}$ value). If the data are unaffected by turbulence or gas slippage, then $r^{2}$ is generally greater than 0.99 . If flow is non-laminar, $r^{2}$ tends to be appreciably lower, and the permeability is determined using Eqs. (A3) or (A4) as appropriate. Repeat measurements suggest that experimental error is always engirdled by the symbol size when plotted graphically.
Figure A1 shows flow rate and pressure data obtained during steady-state permeability measurements on three volcanic samples. For the first example, Fig. A1a-c, flow is laminar, as evident from the linear relation between the volumetric flow rate $\left(Q_{\mathrm{v}}\right)$ and the driving pressure $(\nabla p \bar{p})$. Accordingly, the reciprocal permeability $\left(k_{\text {gas }}^{-1}\right)$ versus $Q_{\mathrm{v}}$ is negative and nonlinear, as is the measured permeability $k_{\text {gas }}$ against the reciprocal mean pressure $\bar{p}^{-1}$. In the second example, flow is turbulent, and the data in Fig. A1d are nonlinear. Applying the correction derived from Fig. A1e (Eq. A3) yields Fig. A1f, where the data are randomly distributed about the mean (no Klinkenberg correction is necessary). Finally, the data shown in Fig. A1g-h highlight that a Klinkenberg correction is necessary (Eq. A4). However, the correction is very slight, as indeed often tends to be the case in volcanic rocks (as opposed to tight materials such as granite). For the LLB data presented in Table 2, Forchheimer corrections were applied to the raw values where appropriate. Permeability values were affected only slightly, increasing by a factor of between 1.03 and 1.41 . 

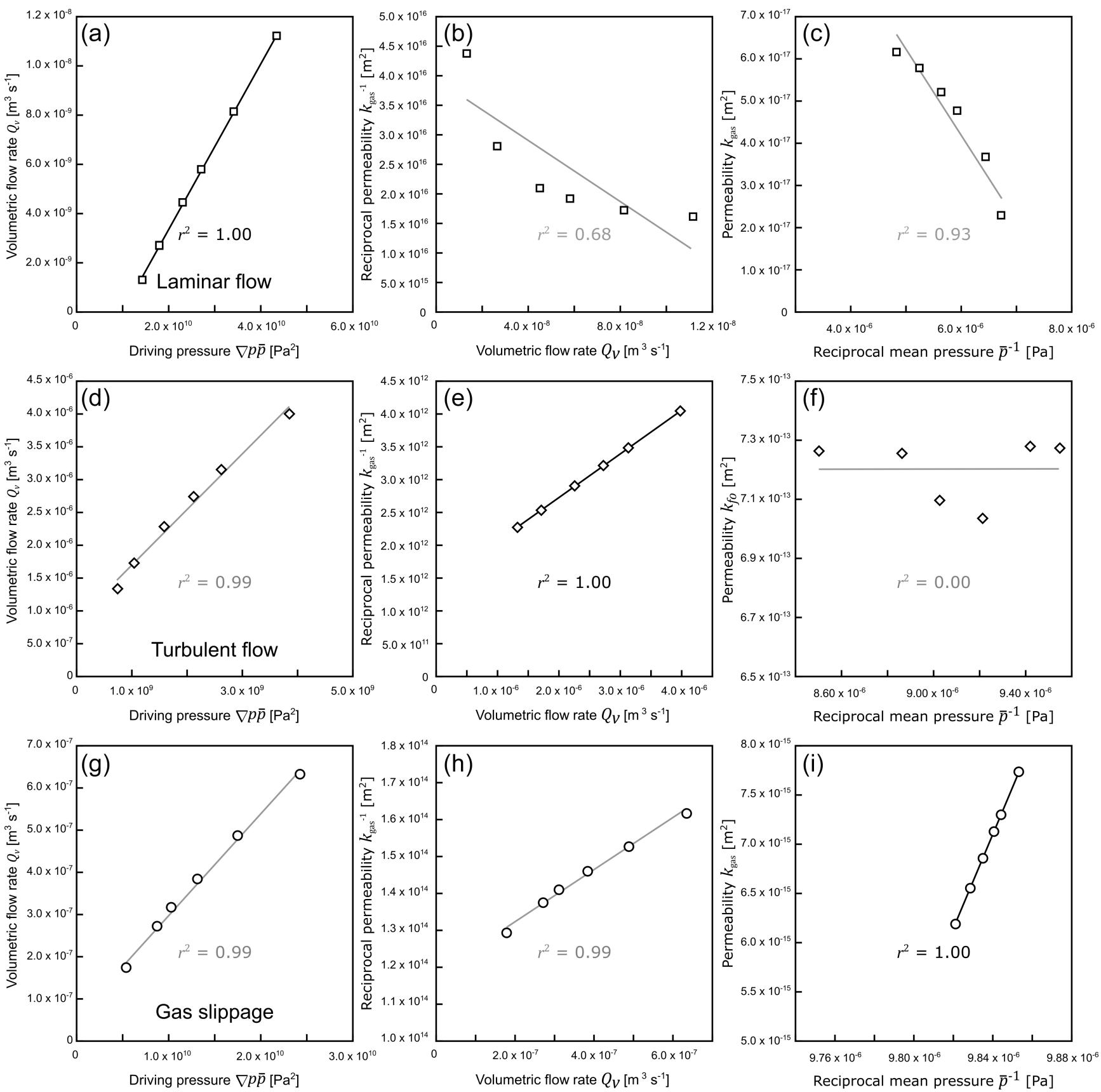

Figure A1. Flow and pressure data. Data obtained during permeability measurements on three rocks. (a-c) Laminar flow in a sample from Whakaari, New Zealand. (d-f) Turbulent flow, in a sample of Ruapehu andesite (New Zealand). (g-i) A small gas slippage effect in a sample of Açores trachyandesite. 
Author contributions. Jamie I. Farquharson, Patrick Baud, and Michael J. Heap designed the experiments, which were performed by Jamie I. Farquharson. Jamie I. Farquharson prepared the manuscript with contributions from all authors.

Competing interests. The authors declare that they have no conflict of interest.

Acknowledgements. Thierry Reuschlé, Alex Schubnel, Luke Griffiths, and Alexandra Kushnir are thanked for inspiring discussions. Fieldwork was funded in part by the framework of the LABEX ANR-11-LABX-0050_G-EAU-THERMIE-PROFONDE and therefore benefits from a funding from the state managed by the French National Research Agency as part of the Investments for the Future programme. Jamie I. Farquharson acknowledges an Initiative d'Excellence (IDEX) "Contrats doctoraux" grant from the French state. Michael J. Heap acknowledges Initiative d'Excellence (IDEX) Attractivité grant "VOLPERM" and a CNRS INSU grant. We are grateful to Nick Varley and Oliver Lamb for field assistance at Volcán de Colima. Fabian Wadsworth and Antonella Longo are thanked for their constructive comments on the paper.

Edited by: Antonella Longo

Reviewed by: F. Wadsworth

\section{References}

Adelinet, M., Fortin, J., Schubnel, A. and Guéguen, Y.: Deformation modes in an Icelandic basalt: from brittle failure to localized deformation bands, J. Volcanol. Geoth. Res., 255, 15-25, 2013.

Alam, A. B., Niioka, M., Fujii, Y., Fukuda, D., and Kodama, J. I.: Effects of confining pressure on the permeability of three rock types under compression, Int. J. Rock Mech. Min., 65, 49-61, 2014.

Barberi, F., Cassano, E., La Torre, P., and Sbrana, A.: Structural evolution of Campi Flegrei caldera in light of volcanological and geophysical data, J. Volcanol. Geoth. Res., 48, 33-49, 1991.

Baud, P., Zhu, W., and Wong, T.-F.: Failure mode and weakening effect of water on sandstone, J. Geophys. Res., 105, 16371-16389, 2000.

Baud, P., Meredith, P., and Townend, E.: Permeability evolution during triaxial compaction of an anisotropic porous sandstone, J. Geophys. Res.-Sol. Ea., 117, B05203, doi:10.1029/2012JB009176, 2012.

Baud, P., Reuschlé, T., Ji, Y., Cheung, C. S., and Wong, T.-F.: Mechanical compaction and strain localization in Bleurswiller sandstone. J. Geophys. Res.-Sol. Ea., 120, 6501-6522, 2015.

Baud, P., Wong, T. F., and Zhu, W.: Effects of porosity and crack density on the compressive strength of rocks, Int. J. Rock Mech. Min., 67, 202-211, 2014.

Baud, P., Vajdova, V., and Wong, T. F.: Shear enhanced compaction and strain localization: Inelastic deformation and constitutive modeling of four porous sandstones, J. Geophys. Res.-Sol. Ea., 111, B12401, doi:10.1029/2005JB004101, 2006.
Bernabé, Y.: June. The effective pressure law for permeability in Chelmsford granite and Barre granite, Int. J. Rock Mech. Min., 23, 267-275, 1986.

Bernard, B., Kueppers, U., and Ortiz, H.: Revisiting the statistical analysis of pyroclast density and porosity data, Solid Earth, 6, 869-879, doi:10.5194/se-6-869-2015, 2015.

Brantut, N., Heap, M. J., Meredith, P. G., and Baud, P.: Timedependent cracking and brittle creep in crustal rocks: A review, J. Struct. Geol., 52, 17-43, 2013.

Cashman, K. V., Thornber, C. R., and Pallister, J. S.: From dome to dust: Shallow crystallization and fragmentation of conduit magma during the 2004-2006 dome extrusion of Mount St. Helens, Washington, US Geological Survey professional paper, 1750, 387-413, 2008.

Chen, Z., Liu, W., Zhang, Y., Yan, D., Yang, D., Zha, M., and Li, L.: Characterization of the paleocrusts of weathered Carboniferous volcanics from the Junggar Basin, western China: Significance as gas reservoirs, Mar. Petrol. Geol., 77, 216-234, 2016.

Chen, Z., Wang, X., Wang, X., Zhang, Y., Yang, D., and Tang, Y.: Characteristics and petroleum origin of the Carboniferous volcanic rock reservoirs in the Shixi Bulge of Junggar Basin, western China, Mar. Petrol. Geol., 80, 517-537, 2017.

Chen, X., Yu, J., Li, H., and Wang, S.: Experimental and Numerical Investigation of Permeability Evolution with Damage of Sandstone Under Triaxial Compression, Rock Mechanics and Rock Engineering, 1-21, 2017b.

Clarke, A. B., Stephens, S., Teasdale, R., Sparks, R. S. J., and Diller, K.: Petrologic constraints on the decompression history of magma prior to Vulcanian explosions at the Soufrière Hills volcano, Montserrat, J. Volcanol. Geoth. Res., 161, 261-274, 2007.

Commer, M., Helwig, S.L., Hördt, A., and Tezkan, B.: Interpretation of long-offset transient electromagnetic data from Mount Merapi, Indonesia, using a three-dimensional optimization approach, J. Geophys. Res.-Sol. Ea., 110, B03207, doi:10.1029/2004JB003206, 2005.

Cubellis, E., Ferri, M., and Luongo, G.: Internal structures of the Campi Flegrei caldera by gravimetric data, J. Volcanol. Geoth. Res., 65, 147-156, 1995.

Darcy, H. P. G.: Les Fontaines publiques de la ville de Dijon, Exposition et application des principes - suivre et des formules - employer dans les questions de distribution d'eau, Exhibition and implementation of the principles to follow and to formulae employ in the issue of water distribution, Victor Dalmont, France, 1856 (in French).

Day, S. J.: Hydrothermal pore fluid pressure and the stability of porous, permeable volcanoes, Geological Society, London, Special Publications, 110, 77-93, 1996.

Delcamp, A., Roberti, G., and de Vries, B. V. W.: Water in volcanoes: evolution, storage and rapid release during landslides, B. Volcanol., 78, 87, doi:10.1007/s00445-016-1082-8, 2016.

Denlinger, R. P. and Hoblitt, R. P.: Cyclic eruptive behavior of silicic volcanoes, Geology, 27, 459-462, 1999.

Dieterich, J. H.: Growth and persistence of Hawaiian volcanic rift zones, J. Geophys. Res.-Sol. Ea., 93, 4258-4270, 1988.

Dzurisin, D.: A comprehensive approach to monitoring volcano deformation as a window on the eruption cycle, Rev. Geophys., 41, doi:10.1029/2001RG000107, 2003. 
Edmonds, M. and Herd, R. A.: A volcanic degassing event at the explosive-effusive transition, Geophys. Res. Lett., 34, L21310, doi:10.1029/2007GL031379, 2007.

Eichelberger, J. C., Carrigan, C. R., Westrich, H. R., and Price, R. H.: Non-explosive silicic volcanism, Nature, 323, 598-602, 1986.

Engelder, J. T.: Cataclasis and the generation of fault gouge, Geol. Soc. Am. Bull., 85, 1515-1522, 1974.

Faoro, I., Vinciguerra, S., Marone, C., Elsworth, D., and Schubnel, A.: Linking permeability to crack density evolution in thermally stressed rocks under cyclic loading, Geophys. Res. Lett., 40, 2590-2595, 2013.

Farquharson, J., Heap, M. J., Baud, P., Reuschlé, T., and Varley, N. R.: Pore pressure embrittlement in a volcanic edifice, B. Volcanol., 78, 1-19, 2016a.

Farquharson, J., Heap, M. J., Varley, N. R., Baud, P., and Reuschlé, T.: Permeability and porosity relationships of edifice-forming andesites: a combined field and laboratory study, J. Volcanol. Geoth. Res., 297, 52-68, 2015.

Farquharson, J. I., Heap, M. J., and Baud, P.: Strain-induced permeability increase in volcanic rock, Geophys. Res. Lett., 43, 1160311610 doi:10.1002/2016GL071540, 2016b.

Farquharson, J. I., Heap, M. J., Lavallée, Y., Varley, N. R., and Baud, P.: Evidence for the development of permeability anisotropy in lava domes and volcanic conduits, J. Volcanol. Geoth. Res., 323, 163-185, 2016c.

Finn, C. A., Deszcz-Pan, M., Anderson, E. D., and John, D. A.: Three-dimensional geophysical mapping of rock alteration and water content at Mount Adams, Washington: Implications for lahar hazards, J. Geophys. Res.-Sol. Ea., 112, B10204, doi:10.1029/2006JB004783, 2007.

Forchheimer, P.: Wasserbewegung durch boden, Water movement through soil, Zeitschrift des Vereines Deutscher Ingenieure, 45, 1788, 1901 (in German).

Fortin, J., Stanchits, S., Vinciguerra, S., and Guéguen, Y.: Influence of thermal and mechanical cracks on permeability and elastic wave velocities in a basalt from Mt. Etna volcano subjected to elevated pressure, Tectonophysics, 503, 60-74, 2011.

Freeze, R. A. and Cherry, J. A.: Groundwater, Englewood, PrenticeHall, 1979.

Gaunt, H. E., Sammonds, P. R., Meredith, P. G., Smith, R., and Pallister, J. S.: Pathways for degassing during the lava dome eruption of Mount St. Helens 2004-2008, Geology, 42, 947-950, 2014.

Gonnermann, H. M. and Manga, M.: Dynamics of magma ascent in the volcanic conduit, Modeling Volcanic Processes: The physics and mathematics of volcanism, edited by: Fagents, S. A., Gregg, T. K. P., and Lopes, R. M. C., Cambridge University Press, 55 pp., 2013.

Gottsmann, J., Camacho, A. G., Martí, J., Wooller, L., Fernández, J., Garcia, A., and Rymer, H.: Shallow structure beneath the Central Volcanic Complex of Tenerife from new gravity data: Implications for its evolution and recent reactivation, Phys. Earth Planet. In., 168, 212-230, 2008.

Heap, M. J., Lavallée, Y., Petrakova, L., Baud, P., Reuschle, T., Varley, N. R., and Dingwell, D. B.: Microstructural controls on the physical and mechanical properties of edifice-forming andesites at Volcan de Colima, Mexico, J. Geophys. Res.-Sol. Ea., 119, 2925-2963, 2014.
Heap, M. J., Baud, P., Meredith, P. G., Vinciguerra, S., Bell, A. F., and Main, I.G.: Brittle creep in basalt and its application to timedependent volcano deformation, Earth Planet. Sc. Lett., 307, $71-$ 82, 2011.

Heap, M. J., Brantut, N., Baud, P., and Meredith, P. G.: Timedependent compaction band formation in sandstone, J. Geophys. Res.-Sol. Ea., 120, 4808-4830, 2015c.

Heap, M. J., Farquharson, J. I., Baud, P., Lavallée, Y., and Reuschlé, T.: Fracture and compaction of andesite in a volcanic edifice, B. Volcanol., 77, 1-19, 2015a.

Heap, M. J., Kennedy, B. M., Pernin, N., Jacquemard, L., Baud, P., Farquharson, J. I., Scheu, B., Lavallée, Y., Gilg, H. A., LethamBrake, M., and Mayer, K.: Mechanical behaviour and failure modes in the Whakaari (White Island volcano) hydrothermal system, New Zealand, J. Volcanol. Geoth. Res., 295, 26-42, 2015 b.

Heap, M. J., Russell, J. K., and Kennedy, L. A.: Mechanical behaviour of dacite from Mount St. Helens (USA): A link between porosity and lava dome extrusion mechanism (dome or spine)?, J. Volcanol. Geoth. Res., 328, 159-177, doi:10.1016/j.jvolgeores.2016.10.015, 2016.

Heap, M. J. and Wadsworth, F. B.: Closing an open system: pore pressure changes in permeable edifice rock at high strain rates, J. Volcanol. Geoth. Res., 315, 40-50, 2016.

Heap, M. J., Violay, M., Wadsworth, F. B., and Vasseur, J.: From rock to magma and back again: The evolution of temperature and deformation mechanism in conduit margin zones, Earth Planet. Sc. Lett., 463, 92-100, 2017.

Heimisson, E. R., Einarsson, P., Sigmundsson, F., and Brandsdóttir, B.: Kilometer-scale Kaiser effect identified in Krafla volcano, Iceland, Geophys. Res. Lett., 42, 7958-7965, 2015.

Hurwitz, S., Kipp, K. L., Ingebritsen, S. E., and Reid, M. E.: Groundwater flow, heat transport, and water table position within volcanic edifices: Implications for volcanic processes in the Cascade Range, J. Geophys. Res.-Sol. Ea., 108, 2557, doi:10.1029/2003JB002565, 2003.

Jónsson, G. and Stefánsson, V.: Density and porosity logging in the IRDP hole, Iceland, J. Geophys. Res.-Sol. Ea., 87, 6619-6630, 1982.

Kempter, K. A., Benner, S. G., and Williams, S. N.: Rincón de la Vieja volcano, Guanacaste province, Costa Rica: geology of the southwestern flank and hazards implications, J. Volcanol. Geoth. Res., 71, 109-127, 1996.

Kennedy, L. A. and Russell, J. K.: Cataclastic production of volcanic ash at Mount Saint Helens, Phys. Chem. Earth, Parts A/B/C, 45, 40-49, 2012.

Kiyama, T., Kita, H., Ishijima, Y., Yanagidani, T., Aoki, K., and Sato, T.: January, Permeability in anisotropic granite under hydrostatic compression and triaxial compression including postfailure region, in: 2nd North American Rock Mechanics Symposium American Rock Mechanics Association, 1996,

Klinkenberg, L. J.: The permeability of porous media to liquids and gases, Drilling and production practice, American Petroleum Institute, 1941

Kovari, K., Tisa, A., Einstein, H. H., and Franklin, J. A.: Suggested methods for determining the strength of rock materials in triaxial compression: revised version, Int. J. Rock Mech. Min., 20, 283 290, 1983.

Kushnir, A. R., Martel, C., Bourdier, J. L., Heap, M. J., Reuschlé, T., Erdmann, S., Komorowski, J. C,. and Cholik, N.: Probing 
permeability and microstructure: Unravelling the role of a lowpermeability dome on the explosivity of Merapi (Indonesia), J. Volcanol. Geoth. Res., 316, 56-71, 2016.

Lavallée, Y., Heap, M. J., Kueppers, U., Kendrick, J. E., and Dingwell, D. B.: The fragility of Volcan de Colima a material constraint, in: Volcan de Colima: managing the threat, edited by: Varley, N. and Komorowski, J. C., Springer, Berlin, 2017.

Le Cloarec, M. F. and Gauthier, P. J.: Merapi Volcano, Central Java, Indonesia: A case study of radionuclide behavior in volcanic gases and its implications for magma dynamics at andesitic volcanoes, J. Geophys. Res.-Sol. Ea., 108, 2243, doi:10.1029/2001JB001709, 2003.

Le Pennec, J. L., Hermitte, D., Dana, I., Pezard, P., Coulon, C., Cochemé, J. J., Mulyadi, E., Ollagnier, F., and Revest, C.: Electrical conductivity and pore-space topology of Merapi lavas: implications for the degassing of porphyritic andesite magmas, Geophys. Res. Lett., 28, 4283-4286, 2001.

Li, N., Wu, H., Feng, Q., Wang, K., Shi, Y., Li, Q., and Luo, X.: Matrix porosity calculation in volcanic and dolomite reservoirs and its application, Appl. Geophys., 6, 287, 2009.

Linde, A. T., Agustsson, K., Sacks, I. S., and Stefansson, R.: Mechanism of the 1991 eruption of Hekla from continuous borehole strain monitoring, Nature, 365, 737, 1993.

Loaiza, S., Fortin, J., Schubnel, A., Gueguen, Y., Vinciguerra, S., and Moreira, M.: Mechanical behavior and localized failure modes in a porous basalt from the Azores, Geophys. Res. Lett., 39, L19304, doi:10.1029/2012GL053218, 2012.

Martys, N. S., Torquato, S., and Bentz, D. P.: Universal scaling of fluid permeability for sphere packings, Phys. Rev. E, 50, 403, 1994.

Massonnet, D., Briole, P., and Arnaud, A.: Deflation of Mount Etna monitored by spaceborne radar interferometry, Nature, 375, 567, 1995.

McPhee, C. A. and Arthur, K. G.: Klinkenberg permeability measurements: problems and practical solutions, in: Advances in Core Evaluation IL Reservoir Appraisal, Proceedings of the 2nd Society of Core Analysts European Core Analysis Symposium, Gordon \& Breach Science Publishers, Philadelphia, 371-391, 1991.

Melnik, O. and Sparks, R. S. J.: Nonlinear dynamics of lava dome extrusion, Nature, 402, 37-41, 1999.

Melnik, O. and Sparks, R. S. J.: Controls on conduit magma flow dynamics during lava dome building eruptions, J. Geophys. Res.Sol. Ea., 110, B02209, doi:10.1029/2004JB003183, 2005.

Millett, J. M., Hole, M. J., Jolley, D. W., Schofield, N., and Campbell, E.: Frontier exploration and the North Atlantic Igneous Province: new insights from a $2.6 \mathrm{~km}$ offshore volcanic sequence in the NE Faroe-Shetland Basin, J. Geol. Soc., 173, 320-336, 2016.

Mitchell, T. M. and Faulkner, D. R.: Experimental measurements of permeability evolution during triaxial compression of initially intact crystalline rocks and implications for fluid flow in fault zones, J. Geophys. Res.-Sol. Ea., 113, B11412, doi:10.1029/2008JB005588, 2008.

Mogi, K.: Relations between the eruptions of various volcanoes and the deformation of the ground surfaces around them, Bulletin of the Earthquake Research Institute, 36, 99-134, 1958.

Mordecai, M., Morris, L. H., and Eng, C.: January, An investigation into the changes of permeability occurring in a sandstone when failed under triaxial stress conditions, in: The 12th US Symposium on Rock Mechanics (USRMS), American Rock Mechanics Association, 1970.

Mueller, S., Scheu, B., Kueppers, U., Spieler, O., Richard, D., and Dingwell, D. B.: The porosity of pyroclasts as an indicator of volcanic explosivity, J. Volcanol. Geoth. Res., 203, 168-174, 2011.

Mueller, S., Scheu, B., Spieler, O., and Dingwell, D. B.: Permeability control on magma fragmentation, Geology, 36, 399-402, 2008.

Nara, Y., Meredith, P. G., Yoneda, T., and Kaneko, K.: Influence of macro-fractures and micro-fractures on permeability and elastic wave velocities in basalt at elevated pressure, Tectonophysics, 503, 52-59, 2011.

Nguyen, C. T., Gonnermann, H. M., and Houghton, B. F.: Explosive to effusive transition during the largest volcanic eruption of the 20th century (Novarupta 1912, Alaska), Geology, 42, 703-706, 2014.

Okumura, S. and Sasaki, O.: Permeability reduction of fractured rhyolite in volcanic conduits and its control on eruption cyclicity, Geology, 42, 843-846, 2014.

Omori, F.: Seismographical Observations of the Fore-shocks, Aftershocks, and After-outbursts of the Great Sakura jima-Eruption of 1914, Bulletin of the Imperial Earthquake Investigation Committee, 8, 353-377, 1920.

Peach, C. J. and Spiers, C. J.: Influence of crystal plastic deformation on dilatancy and permeability development in synthetic salt rock, Tectonophysics, 256, 101-128, 1996.

Read, M. D., Ayling, M. R., Meredith, P. G., and Murrell, S. A.: Microcracking during triaxial deformation of porous rocks monitored by changes in rock physical properties, II, Pore volumometry and acoustic emission measurements on water-saturated rocks, Tectonophysics, 245, 223-235, 1995.

Regnet, J. B., David, C., Fortin, J., Robion, P., Makhloufi, Y., and Collin, P. Y.: Influence of microporosity distribution on the mechanical behavior of oolithic carbonate rocks, Geomechanics for Energy and the Environment, 3, 11-23, 2015.

Rust, A. C., Manga, M., and Cashman, K. V.: Determining flow type, shear rate and shear stress in magmas from bubble shapes and orientations, J. Volcanol. Geoth. Res., 122, 111-132, 2003.

Rust, A. C., Cashman, K. V., and Wallace, P. J.: Magma degassing buffered by vapor flow through brecciated conduit margins, Geology, 32, 349-352, 2004.

Sakuma, S., Kajiwara, T., Nakada, S., Uto, K., and Shimizu, H.: Drilling and logging results of USDP-4-Penetration into the volcanic conduit of Unzen Volcano, Japan, J. Volcanol. Geoth. Res., 175, 1-12, 2008.

Schock, R. N., Heard, H. C., and Stephens, D. R.: Stress-strain behavior of a granodiorite and two graywackes on compression to 20 kilobars, J. Geophys. Res., 78, 5922-5941, 1973.

Sepúlveda, F., Lahsen, A., Bonvalot, S., Cembrano, J., Alvarado, A., and Letelier, P.: Morpho-structural evolution of the Cordón Caulle geothermal region, Southern Volcanic Zone, Chile: Insights from gravity and $40 \mathrm{Ar} / 39 \mathrm{Ar}$ dating, J. Volcanol. Geoth. Res., 148, 165-189, 2005.

Setiawan, A.: Modeling of Gravity Changes on Merapi Volcano: Observed Between 1997-2000, PhD thesis, Darmstadt University of Technology, Darmstadt, Germany, 2002. 
Shimada, M., Ito, K., and Cho, A.: Ductile behavior of a finegrained porous basalt at room temperature and pressures to 3 GPa, Phys. Earth Planet. In., 55, 361-373, 1989.

Shteynberg, G. S. and Solov'yev, T.: The shape of volcanoes and the position of subordinate vents, Izvestia Earth Phys, 5, 83-84, 1976.

Sigmundsson, F., Pinel, V., Lund, B., Albino, F., Pagli, C., Geirsson, H., and Sturkell, E.: Climate effects on volcanism: influence on magmatic systems of loading and unloading from ice mass variations, with examples from Iceland, Philos. T. R. Soc. Lond., 368, 2519-2534, 2010.

Siratovich, P. A., Heap, M. J., Villeneuve, M. C., Cole, J. W., Kennedy, B. M., Davidson, J., and Reuschlé, T.: Mechanical behaviour of the Rotokawa Andesites (New Zealand): Insight into permeability evolution and stress-induced behaviour in an actively utilised geothermal reservoir, Geothermics, 64, 163-179, 2016.

Sparks, R. S. J.: The dynamics of bubble formation and growth in magmas: a review and analysis, J. Volcanol. Geoth. Res., 3, 1-37, 1978.

Sparks, R. S. J.. Causes and consequences of pressurisation in lava dome eruptions, Earth Planet. Sc. Lett., 150, 177-189, 1997.

Tiede, C., Camacho, A. G., Gerstenecker, C., Fernández, J., and Suyanto, I.: Modeling the density at Merapi volcano area, Indonesia, via the inverse gravimetric problem, Geochem. Geophy. Geosy., 6, Q09011, doi:10.1029/2005GC000986, 2005.

Ulusay, R. and Hudson, J. A.: The Complete ISRM Suggested Methods for Rock Characterization, Testing and Monitoring: 1974-2006, International Society for Rock Mechanics, ISBN 978-975-93675-4-1, 2007.

Vajdova, V., Baud, P., and Wong, T.-F.: Permeability evolution during localized deformation in Bentheim sandstone, J. Geophys. Res.-Sol. Ea., 109, B10406, doi:10.1029/2003JB002942, 2004.

van Wyk de Vries, B., Kerle, N., and Petley, D.: Sector collapse forming at Casita volcano, Nicaragua, Geology, 28, 167-170, 2000.

van Wyk de Vries, B. V. W. and Borgia, A.: The role of basement in volcano deformation. Geological Society, London, Special Publications, 110, 95-110, 1996.

van Wyk de Vries, B. V. W. and Matela, R.: Styles of volcanoinduced deformation: numerical models of substratum flexure, spreading and extrusion, J. Volcanol. Geoth. Res., 81, 1-18, 1998.

Vinciguerra, S., Trovato, C., Meredith, P. G., and Benson, P. M.: Relating seismic velocities, thermal cracking and permeability in Mt. Etna and Iceland basalts, Int. J. Rock Mech. Min., 42, 900-910, 2005.

Violay, M., Gibert, B., Mainprice, D., Evans, B., Dautria, J. M., Azais, P., and Pezard, P.: An experimental study of the brittleductile transition of basalt at oceanic crust pressure and temperature conditions. J. Geophys. Res.-Sol. Ea., 117, B03213, doi:10.1029/2011JB008884, 2012.
Violay, M., Gibert, B., Mainprice, D., and Burg, J. P.: Brittle versus ductile deformation as the main control of the deep fluid circulation in oceanic crust, Geophys. Res. Lett., 42, 2767-2773, 2015.

Voight, B., Hoblitt, R. P., Clarke, A. B., Lockhart, A. B., Miller, A., Lynch, L. and McMahon, J.: Remarkable cyclic ground deformation monitored in real-time on Montserrat, and its use in eruption forecasting, Geophys. Res. Lett., 25, 3405-3408, 1998.

Wadge, G., Mattioli, G. S., and Herd, R. A.: Ground deformation at Soufrière Hills Volcano, Montserrat during 1998-2000 measured by radar interferometry and GPS, J. Volcanol. Geoth. Res.,152, 157-173, 2006.

Wadsworth, F. B., Vasseur, J., Scheu, B., Kendrick, J. E., Lavallée, Y., and Dingwell, D. B.: Universal scaling of fluid permeability during volcanic welding and sediment diagenesis, Geology, 44, 219-222, 2016.

Wong, T.-F. and Baud, P.: The brittle-ductile transition in porous rock: A review, J. Struct. Geol., 44, 25-53, 2012.

Wong, T.-F., David, C., and Zhu, W.: The transition from brittle faulting to cataclastic flow in porous sandstones: Mechanical deformation, J. Geophys. Res.-Sol. Ea., 102, 3009-3025, 1997.

Woods, A. W. and Koyaguchi, T.: Transitions between explosive and effusive eruptions of silicic magmas, Nature, 370, 641-644, 1994.

Xiaochun, L., Manabu, T., Zhishen, W., Hitoshi, K., and Takashi, O.: Faulting-induced permeability change in Shirahama sandstone and implication for $\mathrm{CO}_{2}$ aquifer storage, Chinese Journal of Rock Mechanics and Engineering, 22, 995-1001, 2003.

Zhang, J., Wong, T. F., and Davis, D. M.: Micromechanics of pressure-induced grain crushing in porous rocks, J. Geophys. Res.-Sol. Ea., 95, 341-352, 1990.

Zhu, W., Baud, P., and Wong, T.-F.: Micromechanics of cataclastic pore collapse in limestone, J. Geophys. Res.-Sol. Ea., 115, B06209, doi:10.1029/2010JB008046, 2010.

Zhu, W. and Wong, T. F.: The transition from brittle faulting to cataclastic flow: Permeability evolution, J. Geophys. Res.-Sol. Ea., 102, 3027-3041, 1997.

Zhu, W., Baud, P., Vinciguerra, S., and Wong, T. F.: Micromechanics of brittle faulting and cataclastic flow in Alban Hills tuff, J. Geophys. Res.-Sol. Ea., 116, B06206, doi:10.1029/2010JB008046, 2011.

Zhu, W., Baud, P., Vinciguerra, S., and Wong, T. F.: Micromechanics of brittle faulting and cataclastic flow in Mount Etna basalt, J. Geophys. Res.-Sol. Ea., 121, doi:10.1002/2016JB012826, 2016.

Zoback, M. D. and Byerlee, J. D.: The effect of microcrack dilatancy on the permeability of Westerly granite, J. Geophys. Res., 80, 752-755, 1975.

Zucca, J. J., Hill, D. P., and Kovach, R. L.: Crustal structure of Mauna Loa volcano, Hawaii, from seismic refraction and gravity data, B. Seismol. Soc. Am., 72, 1535-1550, 1982. 